\title{
A Strategy for Incorporating Learning Analytics into the Design and Evaluation of a K-12 Science Curriculum
}

\author{
Carlos Monroy, Virginia Snodgrass Rangel, Reid Whitaker \\ Center for Digital Learning and Scholarship \\ Rice University, USA \\ carlos.monroy@rice.edu
}

\begin{abstract}
In this paper, we discuss a scalable approach for integrating learning analytics into an online $\mathrm{K}-12$ science curriculum. A description of the curriculum and the underlying pedagogical framework is followed by a discussion of the challenges to be tackled as part of this integration. We include examples of data visualization based on teacher usage data along with a methodology for examining an inquiry-based science program. With more than one million students and fifty thousand teachers using the curriculum, a massive and rich dataset is continuously updated. This repository depicts teacher and student usage, and offers exciting opportunities to leverage data to improve both teaching and learning. In this paper, we use data from a medium-sized school district, comprising 53 schools, 1,026 teachers, and nearly one-third of a million curriculum visits during the 2012-2013 school year. This growing dataset also poses technical challenges such as data storage, complex aggregation, and analyses with broader implications for pedagogy, big data, and learning.
\end{abstract}

Keywords: Learning analytics, science education, online curriculum, K-12

\section{INTRODUCTION}

Computers, tablets, and mobile devices offer new tools to support learning, both inside and outside the classroom. This development, in turn, has created new opportunities to understand and assess their impact on educators and learners through the collection and analysis of user interaction data. Indeed, a major advantage of online curricula over traditional textbook-based curricula is the ability to capture these user interaction or learning analytics data. Learning analytics is a relatively new, but rapidly growing area of research (First International Conference on Learning Analytics and Knowledge, 2011), whose goal, according to the Society of Learning Analytics, is "understanding and optimizing learning and the environments in which it occurs." Most learning analytics (LA) methods use data generated by the interactions between learners and the Learning Management Systems (LMSs) they use (Pahl, 2004).

Ongoing research in educational data mining and LA suggests that harnessing analytics data can advance new research methodologies in education, help educators better assess their pedagogical practices, and devise innovative educational methods, all with the goal of improving education (Elias, 2011; Campbell \& Oblinger, 2007; Pardo \& Delgado, 2011; Siemens, 2012). LA can leverage improvement through improved educational decision-making (Arnold, 2010; Norris, Baer, Leonard, Pugliese, \& Lefrere, 2008; Vatrapu, Tplovs, Fujita, \& Bull, 2011), clearer institutional and individual goal setting (Hendricks, Plantz, \& Pritchard, 2008), more timely and frequent feedback for students and teachers (Ha, Bae, \& Park, 2000; Hamalainen, Suhonen, Sutinen, \& Toivonen, 2004; Merceron \& Yacef, 2005; Suthers, Ravi, Medina, Joseph, \& Dwyer, 2008), the individualization of teaching and learning (Beck \& Mostow, 2008; Farzan, 2004; Heraud, France, \& Mille, 2004; Lu, 2004; Talavera \& Gaudioso, 2004), and the generation 
(2014). A Strategy for Incorporating Learning Analytics into the Design and Evaluation of a K-12 Science Curriculum. Journal of Learning Analytics, 1(2), 94-125.

of a richer set of data on student behaviour and learning (Baker \& Yacef, 2009; Mazza \& Dimitrova, 2004; Pavlik, Cen, \& Koedinger, 2009).

With the rapidly growing interest in and technical ability to leverage these data in educational settings, there also is a growing sense that many recent educational technology and big data initiatives are detached from what we know about teaching and learning, particularly in the K-12 sector (Junco, 2012; Romero \& Ventura, 2010). While the use of LA has been particularly fruitful in higher education and in online courses where many to all learning activities and interactions take place online, in conventional brick and mortar schools, it remains crucial to incorporate information derived from the other activities that go on in a classroom in order to capture fully the variety of learning experiences taking place. This is particularly important in science education where most experts agree that students need to be "doing" science: conducting experiments, making observations, and building models (Crawford, 2000; Haury, 1993; Keys \& Bryan, 2001). Without data on hands-on activities and classroom discussions, it can be hard to make sense of the LA data gathered by an LMS. It is, therefore, imperative to ensure that the use of LA in the $\mathrm{K}-12$ sector is grounded in relevant pedagogies and serves as a complement to data on faceto-face interactive learning experiences not captured by digital artifacts such as student inquiry, classroom discussions, and hands-on activities. This comprehensive, mixed methods approach ensures that data analyses in LA are not reduced to the mere analysis of clicks and page visits.

Furthermore, LA must be leveraged in ways that both recognize and draw on existing $\mathrm{K}-12$ education research. While LA has an established presence in the business sector and even in higher education, its foray into $\mathrm{K}-12$ education is particularly new and is being driven in large part by the start-up community and venture capital, and less by educators or educational researchers (Culatta, 2012; DeSantis, 2012). Although there is nothing wrong with these drivers, educators are unlikely to buy into new technology and big data initiatives if they are not immediately accessible and relevant to their daily work (Means, Padilla, \& Gallagher, 2010; Watters, 2012; Wayman, Cho, \& Richards, 2010).

This paper expands our ongoing research (Monroy, Snodgrass Rangel, \& Whitaker, 2013) and addresses this gap in the literature by outlining and discussing one strategy for incorporating LA into a broader investigation of how a $\mathrm{K}-12$ online science curriculum is implemented in classrooms. The purpose of our implementation study is to increase teacher and student use of the curriculum through improved design. The strategy is meant to answer the following three key questions about the curriculum:

1. How can we incorporate the LA data into a broader effort to understand how a digital curriculum is used?

2. How can we leverage the LA data to support teachers and administrators?

3. How can we integrate the LA data into the evaluation of the curriculum's impact?

We have developed a three-pronged strategy to address these guiding questions: a technical prong related to the architecture supporting the collection and management of LA data, a quantitative prong related to how the LA data can be utilized to understand the curriculum's use and improve its design, and a final qualitative prong where we collect and analyze qualitative data on teacher (and in the future, student) use of the curriculum.

We begin our discussion by briefly describing the curriculum examined here and its underlying pedagogical model. The technical architecture is explained in section three. In section four, we describe 
(2014). A Strategy for Incorporating Learning Analytics into the Design and Evaluation of a K-12 Science Curriculum. Journal of Learning Analytics, 1(2), 94-125.

several specific techniques we have developed to use the LA data to measure use of the curriculum and provide examples using real data from a school district in Texas. Here, we also discuss several considerations related to the normalization of data. In section five, we describe ways to use datavisualization techniques to support teachers and administrators. Then, in section six, we situate our use of LA data within our broader data strategy for measuring the implementation of the curriculum. In order to demonstrate how this might be accomplished, we provide examples from real data collected in the fall of 2012 from a second district in Texas. Finally, we end with a discussion about the future of data analytics in K-12 education, focusing in particular on the challenges we need to overcome and the potential for educational improvement.

\section{BACKGROUND: STEMSCOPES AND THE 5E+I/A PEDAGOGICAL FRAMEWORK}

STEMscopes is a comprehensive online $\mathrm{K}-12$ science curriculum aligned to Texas state standards and grounded in the $5 \mathrm{E}$ science inquiry model. The curriculum offers a range of hands-on inquiry activities, online activities, and additional supporting resources for teachers for each of the learning standards at each grade level. STEMscopes currently serves about 2,400 schools, more than 50,000 teachers, and over one million students in Texas. These figures represent approximately 40 percent of the state's school districts, making it the most used science curriculum in the state. During the 2012-2013 school year, we gathered more than one hundred million data points generated by districts, schools, and users, both teachers and students. We were able to identify the science standard covered, the grade level, specific steps in the $5 \mathrm{E}+\mathrm{l} / \mathrm{A}$ step, materials accessed, and the weekly assessment results.

The 5E pedagogical model is an inquiry-based learning approach that aims to harness learners' prior knowledge while eliciting interest in new phenomena (Bybee et al., 2006). This instructional model was created and refined by the Biological Science Curriculum Study (BSCS). The 5E acronym stands for the following five steps that comprise a full lesson cycle: engage, explore, explain, elaborate, and evaluate. In the Engage phase, students draw on prior knowledge to raise their interest in and activate their prior knowledge of the new content. During the Explore phase, students take part in activities and experiments that allow them to experience and learn new concepts and skills through active investigations. The Explain phase requires students to explain those new concepts and skills in their own words. New experiences in the Elaborate phase deepen student understanding of the new concepts. Finally, learner understanding is assessed in the Evaluate phase. Teachers are meant to implement lessons following this cycle in order to optimize learning.

The STEMscopes curriculum adds two steps to the basic 5E model: one for intervention and one for acceleration. Intervention activities are designed to support those students still struggling to master the standards, while the acceleration activities are designed for those students who have mastered the concepts and are ready to extend and apply their learning (Whitaker, 2012; Zuiker \& Whitaker, 2013). With these two additional steps, the model becomes the $5 \mathrm{E}+\mathrm{l} / \mathrm{A}$ model. 
(2014). A Strategy for Incorporating Learning Analytics into the Design and Evaluation of a K-12 Science Curriculum. Journal of Learning

Changes from Heat (4.5B)

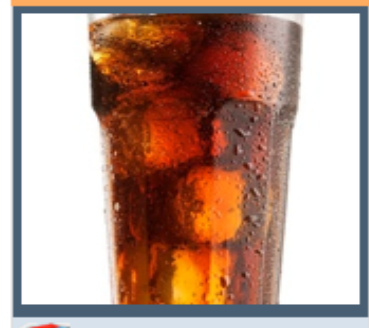

\section{Essentials}

Teacher Background

Standards Correlations

Materials List

Answer Keys

Scope Summary

Key Concepts \& Fundamental

Questions

TEKS Unwrapped

\section{Engage}

Demonstration Presentation

Teacher Instructions

Demonstration Presentation

Starters!

(9) Pre-Assessment

(3) Science Rock

Yexplore

Teacher Guide

Setup Video

Student Guide

Student Journal

(3) Exploration E-Portfolio

6 , Explain

Question Prompts

$\$$ Picture Vocabulary

(3) Student Vocabulary Cards ES:

S Interactive Vocabulary Game

(3) Progress Monitoring [ES]

Assessment

\section{Elaborate}

Next Step Inquiry

Extensions

G Reading Science

Books on Topic

8 Math Connection

(9) Interactive Virtual Investigation

(9) Web Surfing Science!

\section{Evaluate}

S Writing Science!

9 Standards-Based

Assessment

S Interactive Review Game

$\checkmark$ Open-Ended Response

Assessment

\section{Engage}

\section{Demonstration Presentation Teacher Instructions}

This element provides the necessary information for teachers to conduct the Engage Demonstration Presentation activity.

\section{GO>}

\section{Demonstration Presentation}

A pre-made slide presentation to elicit prior knowledge and excite students about learning the topic.

\section{GO>}

\section{Starters!}

A set of ideas and activities that teachers can do to further get students interested in the concept.

\section{GO>}

\section{Pre-Assessment}

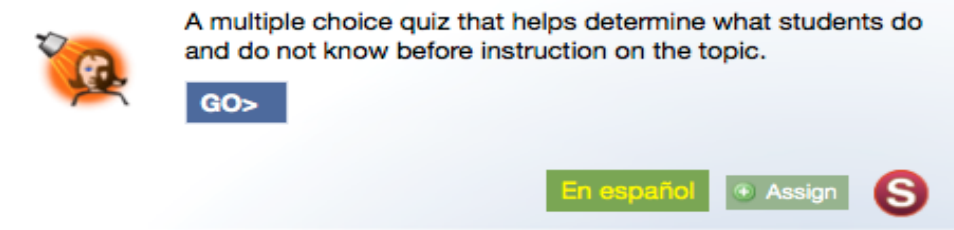

\section{Science Rock}

Songs designed to teach student TEKS content through music and dance.

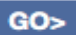

\section{๑) Assign S}

Figure 1: Screen shot of a science unit titled, "Changes from Heat." The column on the left presents elements grouped by each 5E phase (Engage, Explore, Explain, Elaborate, and Evaluate). 
(2014). A Strategy for Incorporating Learning Analytics into the Design and Evaluation of a K-12 Science Curriculum. Journal of Learning Analytics, 1(2), 94-125.

In addition to the online activities and materials, the curriculum also offers accompanying kits that contain the science materials necessary to do every hands-on activity in the curriculum. The kits allow students to conduct science experiments, build models, create simulations, and make observations, thereby offering them a deeper learning experience meant to re-create the work of scientists (Haury, 1993; Minner, Levy, \& Century, 2010). In the Texas version of the curriculum ${ }^{1}$, there are nearly four hundred standards or "scopes" in total across all grade levels. Figure 1 provides an example of what the $5 \mathrm{E}+\mathrm{l} / \mathrm{A}$ model looks like in the curriculum. Specifically, it depicts the $4^{\text {th }}$ grade standard, "Changes from Heat." Components or activities for each of the seven (5E+l/A) steps are presented in the column on the left. They include materials for teachers such as background information on the learning standard, interactive games, and assessments.
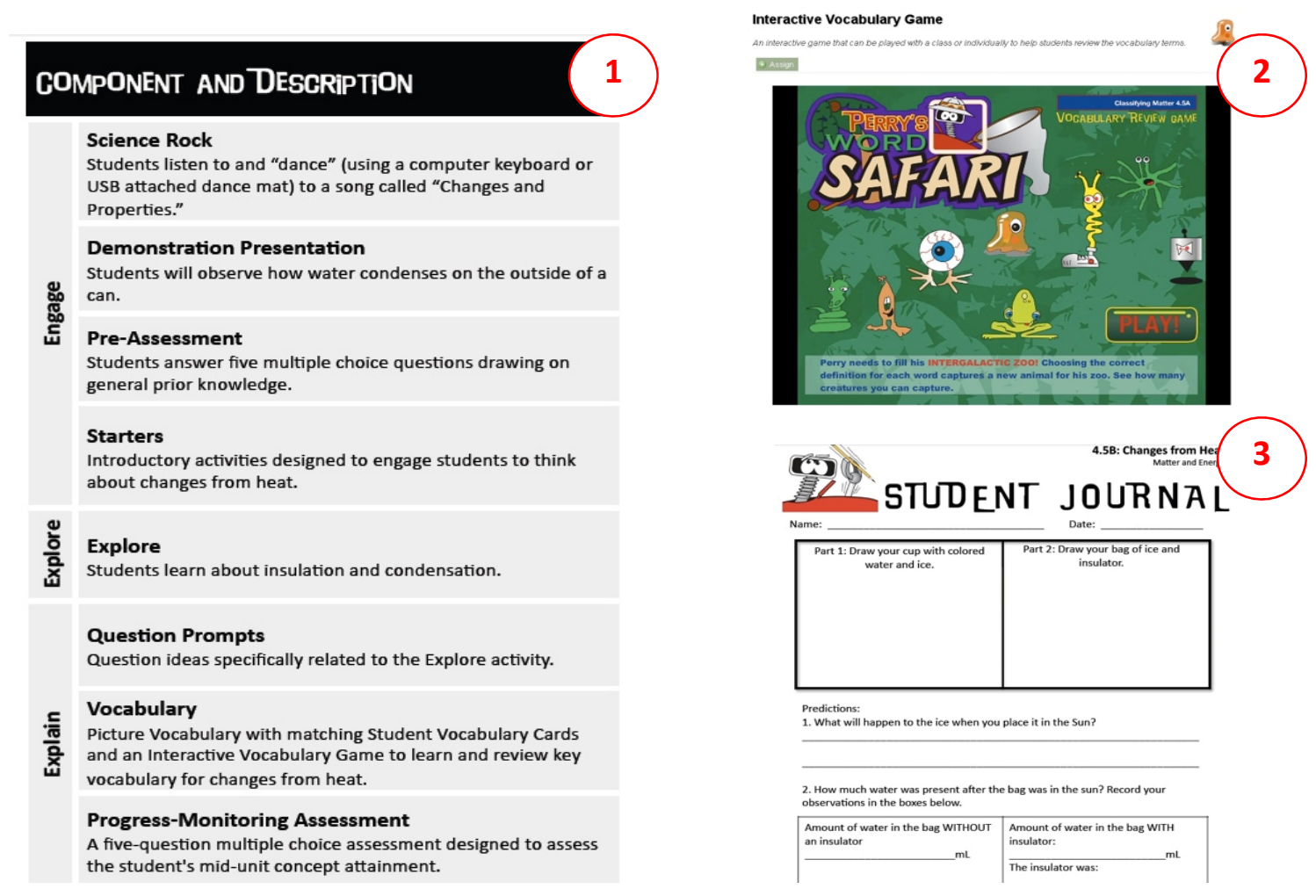

Figure 2. Various elements for one science standard: 1) a partial summary of the content of one unit, 2) an interactive game, and 3) a student journal.

Figure 2 shows three elements within a scope: 1) an overview of a unit's content in the context of the $5 \mathrm{E}+\mathrm{l} / \mathrm{A}$ model, which provides a snapshot of all the components a teacher can find for that scope and is intended for class planning purposes; 2) an interactive game in the Explain phase that offers an engaging

\footnotetext{
${ }^{1}$ There also is a national version created to help teachers implement the Next Generation Science Standards (NGSS), but the NGSS version does not follow the $5 E+1 / A$ model.
} 
(2014). A Strategy for Incorporating Learning Analytics into the Design and Evaluation of a K-12 Science Curriculum. Journal of Learning Analytics, 1(2), 94-125.

opportunity for students to practice new content vocabulary; and 3) a student journal sheet that can be used by students when completing hands-on activities as part of the Explore step.

\section{AN ARCHITECTURE FOR SUPPORTING LEARNING ANALYTICS}

As an online curriculum, STEMscopes creates an environment where data is constantly generated and stored as teachers and students use the curriculum on a daily basis. For this reason, the architecture enables the curation, storage, and processing of that large amount of data. As an example, during the 2012-2013 school year, nearly a quarter of a million interactions with the curriculum were captured each day. This volume of data demands techniques from the areas of databases, data warehouses, and big data. We have designed a distributed data warehouse environment that allows us to scale the storage and processing of user-generated data.

To serve our storage and computing needs, we employ four separate high-end computer servers from a cloud-computing provider. Figure 3 depicts the architecture and interaction among the main servers. Each one of these servers handles specific types of data and requests. The Production Server (PS) is an Nginx web-server, which processes web-client requests via a Ruby on Rails application. Account information such as user names, passwords, and account expiration dates, as well as curriculum taxonomy and state science standards are stored in the Production Database Server (PDBS). Anonymized events data generated by users interacting with the curriculum are stored in the Analytics Storage Server. These events are objects created by the Rails application on the Production Server (PS) and transmitted as encrypted packages via an HTTPS (Hyper Text Transfer Protocol Secure) session. At the end of the day, an automatic process harvests all events generated the previous day (stored in the Analytics Storage Server) and loads them into the Analytics Processing Server (APS). Once the data are loaded, a series of scripts are triggered, which calculate our analytics variables and aggregate results by user, school, and district levels. These results include information about visits by science standard, $5 \mathrm{E}+\mathrm{l} / \mathrm{A}$ step, and curriculum element used. Similarly, the analytics variables are calculated at the end of each week, month, and year. Upon completion, the calculated data are transferred to the Dashboard Data Server (DDS).

Although the current infrastructure is robust enough for our immediate needs, as we introduce more sophisticated analyses, such as machine learning, data mining algorithms, simulations, and computational linguistics, we envision the use of new methodologies in the realm of big data (Jagadish, 2012; Pavlo, Paulson, \& Rasin, 2009). We recently began experimenting with Hadoop (Venner, 2009) and the Map Reduce paradigm, an open source framework that enables distributed high-intensive computing for processing extremely large amounts of data. For instance, a process employing optimized queries and accessing pre-processed aggregated data for calculating twenty-five analytics variables for all teachers during the 2012-2013 school year takes approximately eight days to complete. Thus, we need to plan a scalable infrastructure as we begin calculating content- and user-based models derived from data spanning several years, across multiple schools, districts, and states along with recent usergenerated data. Among the practical benefits of this big data approach to our K-12 curriculum are to allow the use of large clustering and machine learning algorithms for supporting personalized learning in the future. 
(2014). A Strategy for Incorporating Learning Analytics into the Design and Evaluation of a K-12 Science Curriculum. Journal of Learning Analytics, 1(2), 94-125.

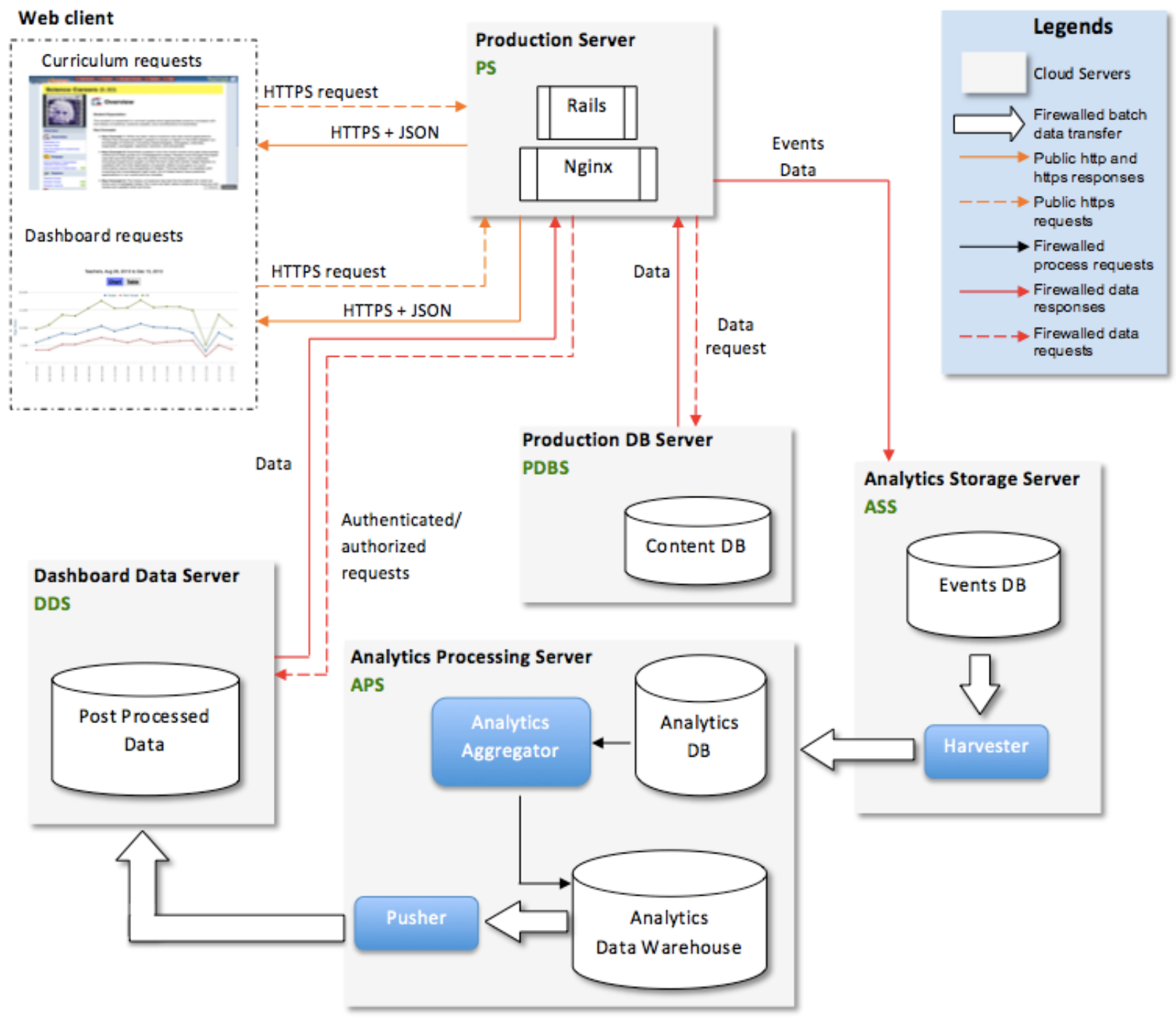

Figure 3. Curriculum architecture and processes for storing, processing, and transferring data

\section{LEARNING ANALYTICS TECHNIQUES FOR MEASURING CURRICULUM USE}

The first research question that we posed is how researchers can utilize LA data to understand how and how much teachers and students use the curriculum. This information is useful both to the curriculum developers as well as to researchers investigating the curriculum's effectiveness. In this section, we focus on the first. The 5E+1/A inquiry model described above guides the analysis of all data collected because without this pedagogical grounding, the data patterns at best have no meaning, and at worst can be attributed the wrong meaning (Atkinson \& Wiley, 2011; Long \& Siemens, 2011). The model's underlying theory of learning, constructivism, is also used to answer important questions about curriculum implementation and how students learn best (Bybee et al., 2006). For example, constructivism and the $5 \mathrm{E}$ model assume that students learn best by exploring concepts before they are 
(2014). A Strategy for Incorporating Learning Analytics into the Design and Evaluation of a K-12 Science Curriculum. Journal of Learning Analytics, 1(2), 94-125.

presented with formal explanations of the content. An important task, then, is to examine whether teachers and students appear to use the steps and corresponding activities in this intended order.

STEMscopes, however, also was created with the understanding that teachers want flexibility in how they teach. In practice, this means that a teacher can access and use any part of the lesson cycle when they deem most appropriate for their students, and most teachers do adapt the lesson cycle and the activities contained within them to their classroom needs (e.g., using components in a different order, changing them, or skipping some of them; Cho \& Wayman, 2014; Hew \& Brush, 2007; Keengwe, Onchwari, \& Wachira, 2008; Koehler \& Mishra, 2005; Lawless \& Pellegrino, 2007; Leonardi, 2009; Orlikowski, 2000). This recognition creates a fundamental challenge for the curriculum designers who also believe that the structure of the $5 \mathrm{E}+\mathrm{l} / \mathrm{A}$ lesson cycle is the best learning path.

This paradox creates a need to understand precisely what teachers and students are doing in their classrooms, and what these patterns of use mean for curriculum development and improvement. We have developed a strategy to complement a more traditional approach to measuring use or implementation with LA data (primarily analyzing teacher use). In the rest of the section, we describe two LA measures that examine the frequency and the ways in which teachers access the curriculum, and three ways we normalize the data to compare across teachers, schools, etc., and to conduct other analyses.

All data were generated at the teacher level and come from a medium-sized school district in Texas during the 2012-2013 school year. ${ }^{2}$ We selected this district because of an ongoing evaluation agreement and because it is one of the top districts in terms of curriculum usage. No identifiable information about district, school, or teacher was used. The original sample included 1,026 users and 53 schools. We discarded 18 users since seven were categorized as administrators and 11 did not have any visits to the actual content. We also removed 6 schools ( 5 high schools and one alternative education) because they were only piloting the curriculum. The final sample included 36 elementary and 11 middle schools with a total of 898 and 88 teachers, respectively.

\subsection{A Pedagogy-Focused Approach to Measuring Use}

It is not enough to know how often the curriculum was visited. Because the curriculum was designed using a specific pedagogical model, the $5 \mathrm{E}+\mathrm{l} / \mathrm{A}$ lesson model, our analyses must try to uncover to what extent teacher use of the curriculum follows the model. Though there are multiple ways to measure how teachers use the curriculum with LA data, here we discuss two: the proportion of visits to each of the $5 \mathrm{E}+\mathrm{l} / \mathrm{A}$ steps and the proportion of visits that are "inquiry-focused."

First, for each teacher the total number of visits to individual steps in the 5E+1/A framework was calculated. Teachers were then grouped according to their most visited step. The chart on the left in Figure 4 shows the percentage of teachers for whom each step was the most used. For instance, Explore was the most visited step for 360 (40\%) elementary teachers and 13 (14\%) middle school teachers; Engage was the most visited step for 242 (26\%) elementary teachers, etc. Conversely, Acceleration was

\footnotetext{
${ }^{2}$ We have found that student use of the curriculum is relatively low, which we assume is due to the limited number of activities that students can complete online, as well as limited school access to computers and other digital devices.
} 
the most visited for only 3 percent of elementary teachers and about 1 percent of middle school teachers. The chart on the right depicts the percentage of visits for each step. Explore was the most visited step for elementary schools teachers with 25 percent of the visits, followed by Engage with 22 percent. For middle schools, the most visited step was Explain (21\%) followed by Explore and Elaborate (18\% each). What these charts mean is that, overall, most visits by elementary teachers are to the hands-on activities of the curriculum. In middle school, the same is true - the most visited step is Explore. Interestingly, middle school teachers access the intervention activities substantially more than do elementary teachers.
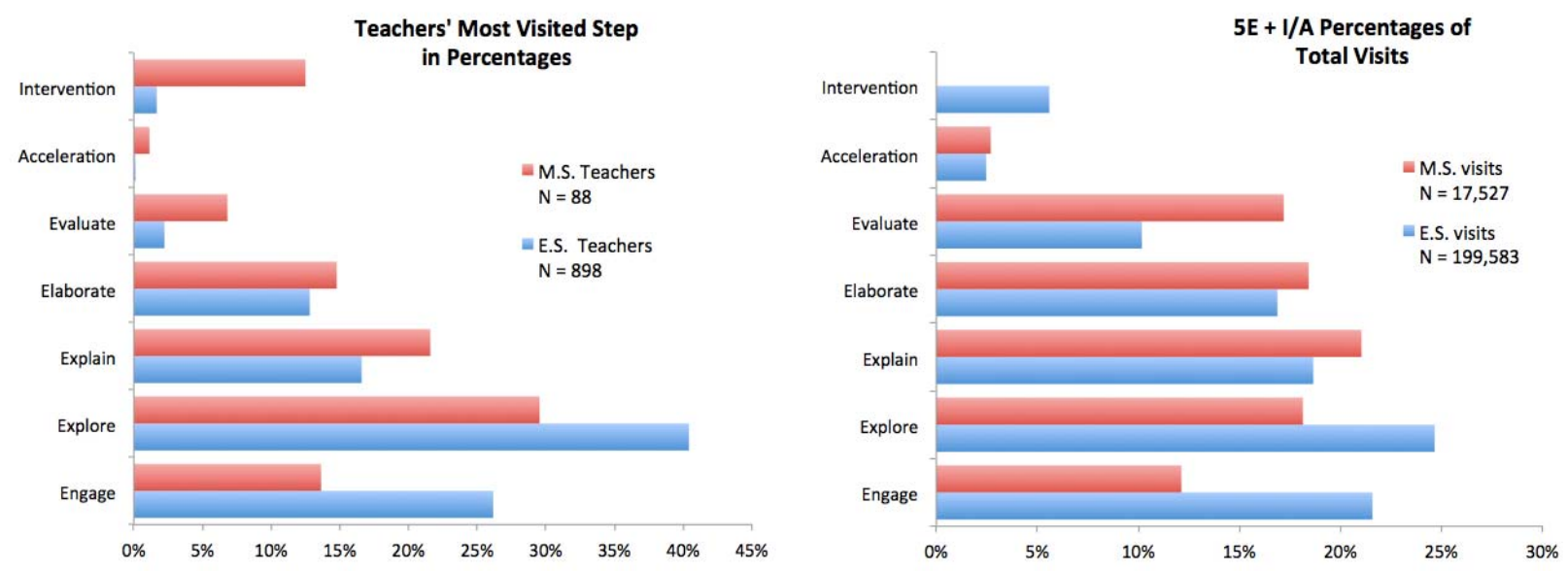

Figure 4: Percentage of teachers for each one of the most used steps (left). Percentage of visits to each $5 \mathrm{E}+\mathrm{l} / \mathrm{A}$ step (right)

Examining teacher use of the curriculum is quite complex and has continually required us to refine what we want to know, usually leading to more nuanced questions. Even the most basic question about frequency of use has many possible answers that require different approaches for calculating variables. For instance, we can capture overall use for each teacher who has an account, but this tells us nothing about how frequently they use specific components; it might simply be that they sign in and out. Therefore, we also calculated how frequently teachers use individual units (there is one unit for each state standard), different steps of the model, and other components within the curriculum (e.g., teacher background material). We also have drilled down further by weighting these statistics by the number of grades a teacher teaches or the number of science topics covered. In this way, we have begun to deal with questions of data normalization, which we will discuss more below.

Questions of time introduce additional complexity. The analytics can tell us how long a teacher is logged in, when the first and last logins were, how long a teacher spends on each page, and on how many different days a teacher actually accesses the website. These can help normalize data as well as give us additional information about how teachers use the curriculum. For example, teacher activity for a sample of teachers in the district in our study throughout the 2012-2013 school year showed a great deal of variation in actual use. These data are summarized in Table 1 below. For elementary schools (36 schools and 898 teachers), on average, teachers visited the curriculum 329 times, with a minimum of 2 and maximum of 4,784 visits; the number of days on which teachers actually log in to access curriculum content averages 30 (minimum=1 and maximum=175 days). 
(2014). A Strategy for Incorporating Learning Analytics into the Design and Evaluation of a K-12 Science Curriculum. Journal of Learning Analytics, 1(2), 94-125.

We also found variation in the time span during which teachers actively use their curriculum accounts (from first login to last login) for the period of interest. The range was from one day to 277 days, with an average of 181 days. We calculated the percent of the total time (in days) that teachers were actively logged into the website; this statistic ranged from $0 \%$ to $100 \%$ of the time with an average of $22 \%$. We also adjusted this figure to take into account the number of grade levels the teachers teach; some teach only one grade, while others teach science to multiple grades. Finally, on average teachers visited a science standard 18 times, while the average of visits by grade level was 199 times. Results for middle schools are shown in the bottom part of Table 1.

Table 1. Teacher data on visits to STEMscopes

\begin{tabular}{|c|c|c|c|c|c|c|c|c|}
\hline & $\begin{array}{l}\text { Total } \\
\text { visits }\end{array}$ & $\begin{array}{l}\text { Number of } \\
\text { different } \\
\text { days } \\
\text { teachers } \\
\text { logged in }\end{array}$ & $\begin{array}{l}\text { Time span } \\
\text { for visits (in } \\
\text { days) }\end{array}$ & $\begin{array}{l}\text { Total time span } \\
\text { weighted by } \\
\text { number of } \\
\text { unique days } \\
\text { teacher logged in } \\
\text { (\%) }\end{array}$ & $\begin{array}{l}\text { Number of } \\
\text { science } \\
\text { topics } \\
\text { taught }\end{array}$ & $\begin{array}{l}\text { Number of } \\
\text { grade levels } \\
\text { taught }\end{array}$ & $\begin{array}{l}\text { Avg. visits } \\
\text { by science } \\
\text { topic }\end{array}$ & $\begin{array}{l}\text { Avg. visits } \\
\text { by grade } \\
\text { level }\end{array}$ \\
\hline \multicolumn{9}{|c|}{$\begin{array}{l}\text { Elementary School } \\
\text { Teachers } \mathrm{N}=\mathbf{8 9 8}\end{array}$} \\
\hline Mean & 329 & 30 & 181 & 0.22 & 15 & 2 & 18 & 199 \\
\hline Median & 191 & 21 & 212 & 0.14 & 13 & 1 & 15 & 128 \\
\hline Minimum & 2 & 1 & 1 & 0.01 & 1 & 1 & 2 & 2 \\
\hline Maximum & 4,784 & 175 & 277 & 1.00 & 161 & 9 & 102 & 1,672 \\
\hline \multicolumn{9}{|c|}{$\begin{array}{l}\text { Middle School Teachers } \\
\mathrm{N}=\mathbf{8 8}\end{array}$} \\
\hline Mean & 302 & 22 & 161 & 0.26 & 16 & 2 & 15 & 166 \\
\hline Median & 122 & 11 & 194 & 0.13 & 13 & 2 & 11 & 53 \\
\hline Minimum & 3 & 1 & 1 & 0.01 & 1 & 1 & 2 & 2 \\
\hline Maximum & 3,897 & 159 & 277 & 1.00 & 90 & 9 & 169 & 3,897 \\
\hline
\end{tabular}

The user analytics variables ranged substantially across schools. Among the main reasons for variation in the number of visits, we identified four: number of standards taught, number of grades taught, longevity of the accounts, and number of different days visited. Longevity represents the number of days elapsed since the user account was created. Therefore, older accounts would tend to have more visits, while newer accounts fewer visits. In the following sections we discuss the effect of these variables on the number of visits to the curriculum.

$$
I I C=\frac{\sum(E n+E x+E p)}{\sum V}
$$

Formula 1

There are many ways to measure use from a pedagogical perspective, and we have developed various indices that allow us to conduct richer analyses of teacher use of the curriculum. A comprehensive description and use of these indices, however, is beyond the scope of this paper. The Inquiry Instruction Contribution Index (IIC Index, depicted in Formula 1 below) is one way to measure use. To illustrate our approach, here we describe the application of the IIC to the total number of visits to the curriculum: 
(2014). A Strategy for Incorporating Learning Analytics into the Design and Evaluation of a K-12 Science Curriculum. Journal of Learning Analytics, 1(2), 94-125.

Specifically, the IIC measures the proportional contribution of the three most "inquiry-based" 5E steps of the lesson cycle (Engage, Explore, and Explain) to the overall curriculum usage (V) for each science standard. This index is important for pedagogical reasons: constructivism and the 5E model favour learning through hands-on, student-centred exploration, and we therefore have an interest in knowing what the proportion of teacher visits are to the more inquiry-based steps and activities. The index provides a summary statistic describing the level of inquiry in the classroom: a figure closer to 0 would suggest relatively little inquiry, whereas a figure closer to 1 would suggest more inquiry focus in a classroom.

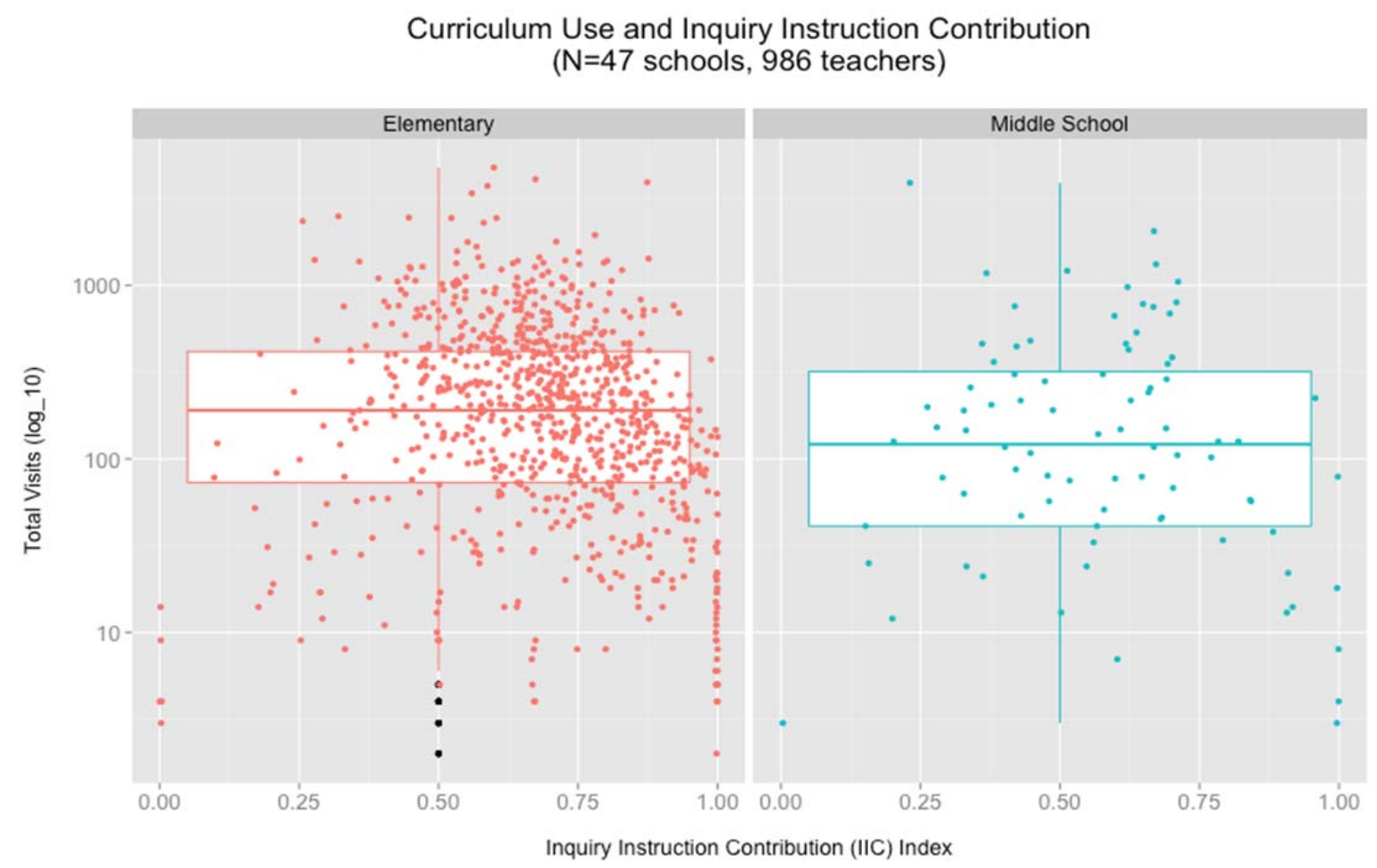

Figure 5: Boxplots depicting teacher visits to the curriculum ( $Y$ axis in log 10 scale) and Inquiry Instruction Contribution Index ( $X$ axis).

Although it is difficult to determine a "perfect" use dosage, our curriculum design team suggests that between two-thirds and three-quarters of the total curriculum visits should be dedicated to the Engage, Explore, and Explain steps. In Figure 5, we compare curriculum visits (Y-axis) with the IIC index (X-axis) for each teacher across elementary ( $N=36$ schools, 898 teachers) and middle schools ( $N=11$ schools, 88 teachers). The comparison indicates that the level of the inquiry focus varies according to school level.

Table 2 shows the distribution of total visits and IIC for teachers in both elementary and middle schools. Elementary schools in this district have the highest level of total use with an average of 329 and maximum of 4,784, and most of that use clusters in the higher range of the IIC index, which suggests both that the elementary teachers visit the Engage, Explore, and Explain steps a fair amount, and that there might be a relationship between higher use of the curriculum and a more inquiry-focused classroom. In contrast, the middle school teachers have lower use with an average of 302 and maximum 
(2014). A Strategy for Incorporating Learning Analytics into the Design and Evaluation of a K-12 Science Curriculum. Journal of Learning Analytics, 1(2), 94-125.

of 3,897 , and their IICs are more evenly distributed, that is, the frequency of teacher visits does not appear to be related to the inquiry focus of a teacher's classroom.

Table 2. Distribution of total visits and IIC

\begin{tabular}{|c|c|c|c|c|}
\hline & \multicolumn{2}{|c|}{$\begin{array}{c}\text { Elementary School } \\
\text { Teachers }\end{array}$} & \multicolumn{2}{|c|}{$\begin{array}{l}\text { Middle School } \\
\text { Teachers }\end{array}$} \\
\hline & $\begin{array}{l}\text { Total } \\
\text { visits }\end{array}$ & IIC & $\begin{array}{l}\text { Total } \\
\text { Visits }\end{array}$ & $\| C$ \\
\hline Minimum & 2 & 0.00 & 3 & 0.00 \\
\hline 1st quartile & 73 & 0.58 & 41 & 0.42 \\
\hline Median & 191 & 0.71 & 122 & 0.60 \\
\hline Mean & 329 & 0.69 & 302 & 0.58 \\
\hline 3rd quartile & 416 & 0.83 & 319 & 0.70 \\
\hline Maximum & 4784 & 1.00 & 3897 & 1.00 \\
\hline
\end{tabular}

Broken down this way, the IIC data start to paint a picture of how teachers use the curriculum. These data might then be used to revise the middle and high school portions of the curriculum to see where improvements might be made to the more inquiry-based steps and activities. On the other hand, these data might be used to identify needs for professional development and coaching that can be embedded into the curriculum (e.g., middle and high school teachers may need support in figuring out how to integrate more hands-on activities into their lessons).

\subsection{Number of science standards taught}

In addition to creating LA-based measures of curriculum use, we must also ensure that the data are comparable across different units and levels of analysis. One important consideration is the number of science standards taught. Within their accounts, teachers can access all state standards throughout the school year. Because different districts and even schools may have their own curriculum scope and sequence, it is necessary to examine overall teacher use while taking into consideration the number of standards that have been taught. Without this form of normalization, a teacher in a district with one scope and sequence may appear to use the curriculum more than a teacher working under a different scope and sequence.

Figure 6 illustrates this relationship. The total number of teacher visits is on the Y-axis (in log 10 scale) and the total number of science standards taught is on the $\mathrm{X}$-axis. Each point in the graph corresponds to a teacher and the dotted line is the mean number of visits. The graph points to a weak but positive relationship: as the number of science standards accessed increases, so does the number of the overall visits. Without taking this relationship into consideration, we might have a biased understanding of curriculum use.

\subsection{Grade levels accessed}

A second variable that influences the total number of teacher visits to the curriculum is the number of grade levels that a teacher accesses. We have found in our research that teachers access standards from more than one grade level for different reasons: some teach science to more than one grade level, while 
others pull activities from previous grade levels as a review, and still other teachers share accounts. Unfortunately, it is only possible to know why teachers access different grade levels if you ask them directly through a survey, interview, or focus group. It is possible, however, to control for the number of grade levels accessed as another way to normalize overall use: without this control, a teacher account that accesses numerous grade levels might have more visits to the curriculum, even though the teacher may not teach more science. Figure 7 depicts the weak but positive relationship between total visits ( $Y$ axis, in log 10 scale) and number of grades taught (X-axis). Each point represents one teacher.

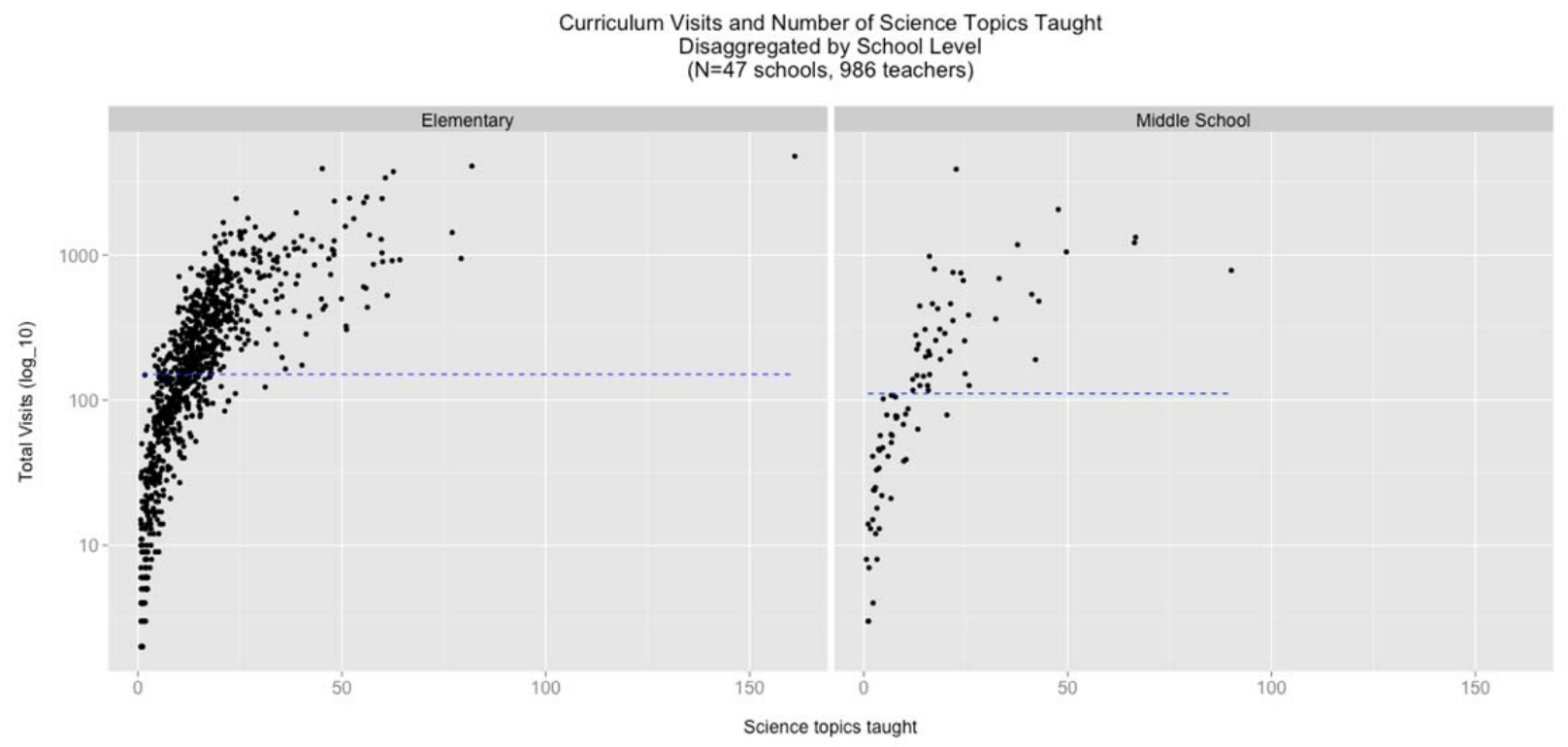

Figure 6. Total number of visits to the curriculum and number of science standards taught.

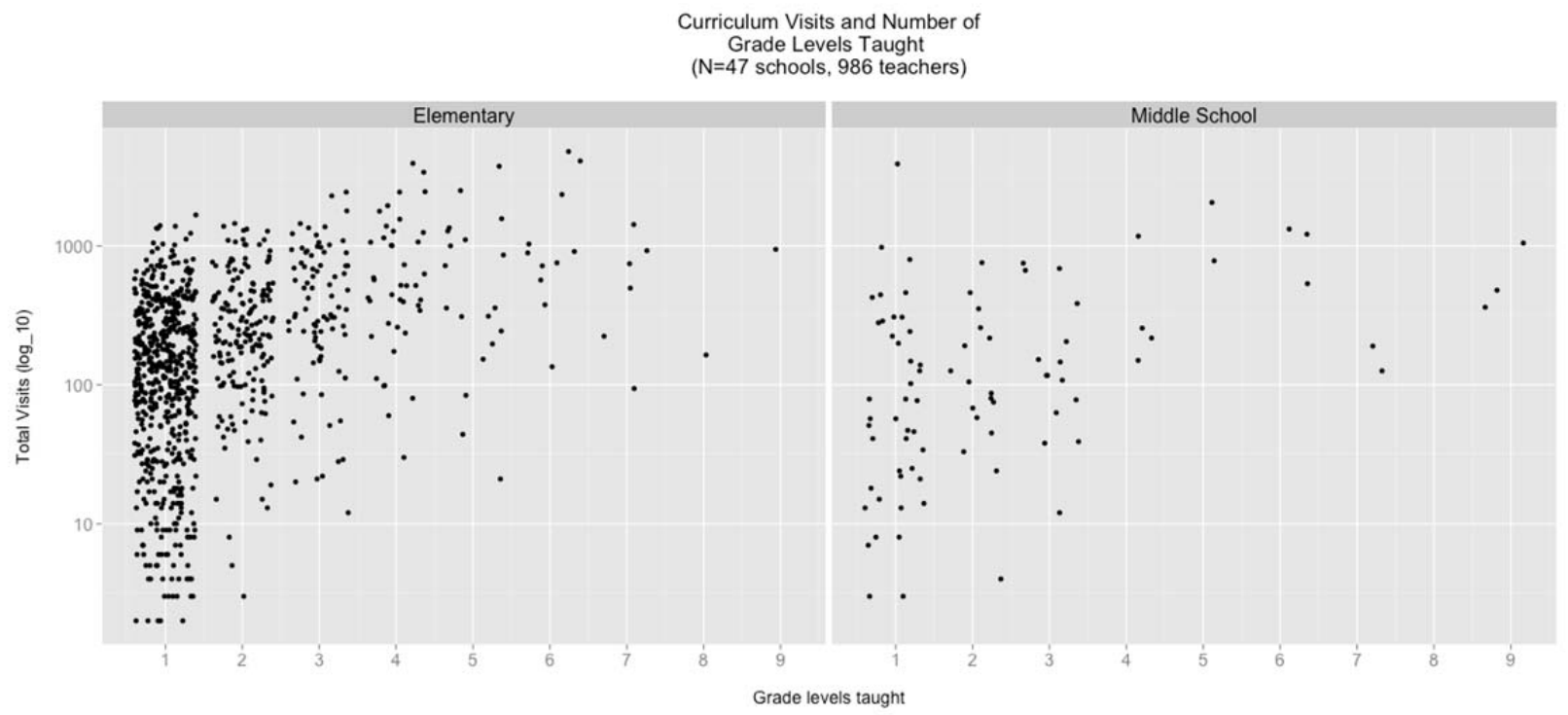

Figure 7. Total number of visits to the curriculum and number of grade levels taught. 
(2014). A Strategy for Incorporating Learning Analytics into the Design and Evaluation of a K-12 Science Curriculum. Journal of Learning Analytics, 1(2), 94-125.

\subsection{Longevity of accounts}

A third consideration for data normalization is the longevity of teacher accounts. Longevity refers to the number of days elapsed between the creation of an account and a second given date (e.g., the end of the school year, the last day of use, etc.). Teachers do not always activate their online accounts at the same time, which we hypothesized would affect the total number of visits to the curriculum: teachers with "older" accounts should have a higher number of overall visits, but this might not mean that they teach more science. Figure 8 shows number of visits on the Y-axis in log 10 scale and longevity of the account in days on the $X$-axis as of the first day of the school year, disaggregated by school level. Values closer to the left are newer accounts (negative values indicate days elapsed since the beginning of the school year and the date when the account was created), whereas values to the right correspond to older accounts (positive values indicate the number of days that accounts have been active). Most of the schools show two clusters of account longevity, one around 0 days and the other between 550 and 600 days. These clusters represent the creation of new accounts at the beginning of each school year. The plots do not show defined trend lines and therefore do not suggest a correlation between use and longevity. However, elementary schools created more new accounts once the school year had started than middle schools did.

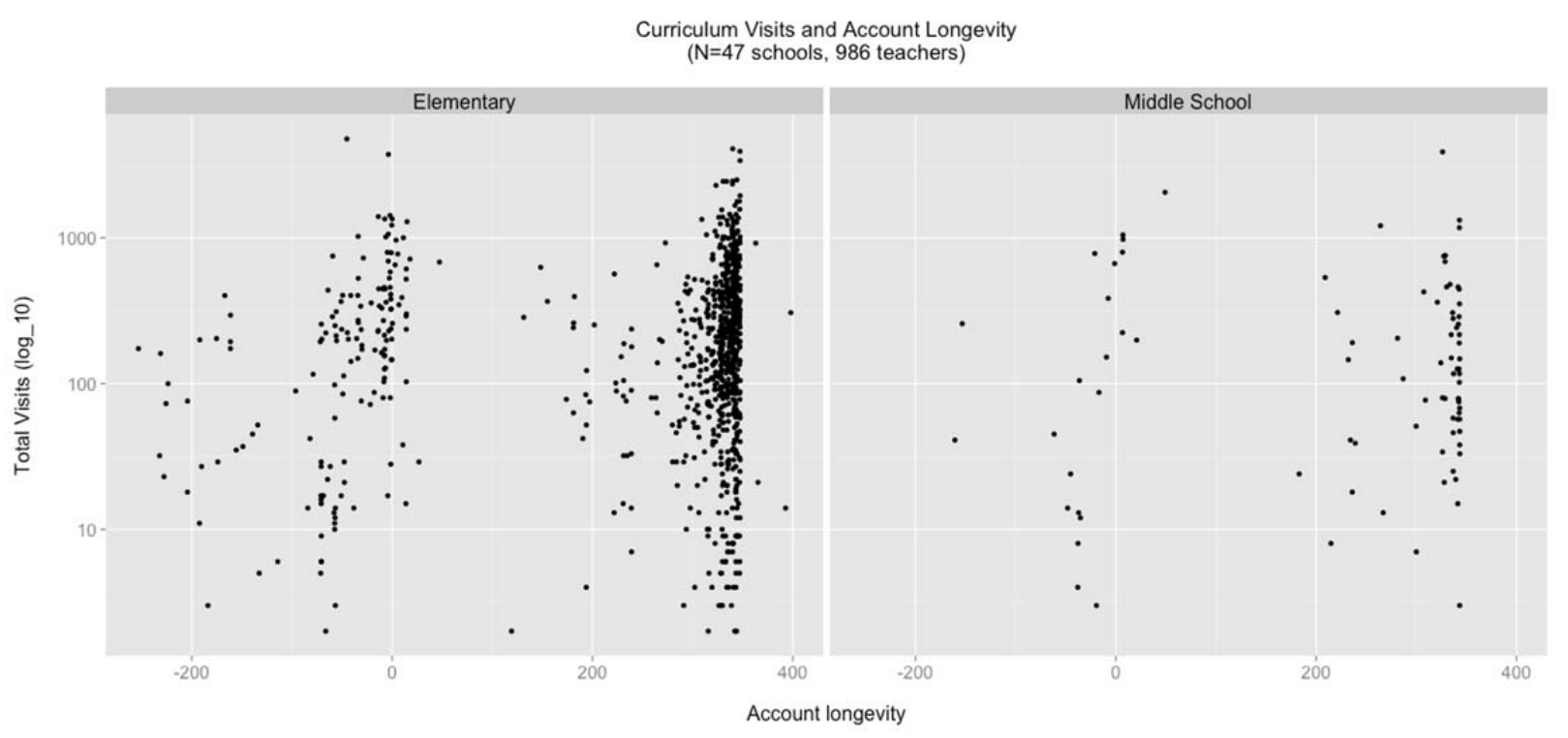

Figure 8. Total visits to the curriculum and account longevity.

\subsection{Proportion of days visited}

Finally, another way to think about teacher use of the curriculum is to measure the time during which they have accessed it actively. To do this, we created a variable that represents the number of unique days a teacher has accessed the curriculum divided by the teacher's total log-in time span in days (calculated as the difference, in days, between the first and last day a teacher logged in). Values closer to 1.0 indicate a teacher who has logged in virtually every day; a value of 0.5 indicates a teacher who has logged in nearly half of the time they had an active account; and values closer to 0.0 indicate a teacher who seldom logged in. For example, a teacher who uses the curriculum on a daily basis will have more unique days than one who accesses it once a week. It is important to note that this measure does not 
(2014). A Strategy for Incorporating Learning Analytics into the Design and Evaluation of a K-12 Science Curriculum. Journal of Learning Analytics, 1(2), 94-125.

take into account the amount of content accessed within a single visit. In other words, it is possible that one teacher with more unique visits than another has accessed less content during each visit such that the two teachers have accessed the same amount of content, or such that the teacher with fewer unique visits actually has accessed more content.

Figure 9 depicts the relationship between the total visits and the proportion of days visited. Total visits on the $\mathrm{Y}$-axis are in log 10 scale, and the proportion of days visited on the $\mathrm{X}$-axis ranges from 0.0 to 1.0. The elementary school graph shows two clusters, the first of which depicts a growing trend in total visits as the proportion of days visited increases (between 0 and 0.5 ). The second cluster shows a small number of teachers with 100\% proportion but very low total visits (approximately less than 75 visits for the entire school year). Middle schools show a similar pattern, with the exception that the proportion of visits ranged approximately between 0.0 and 0.35 .

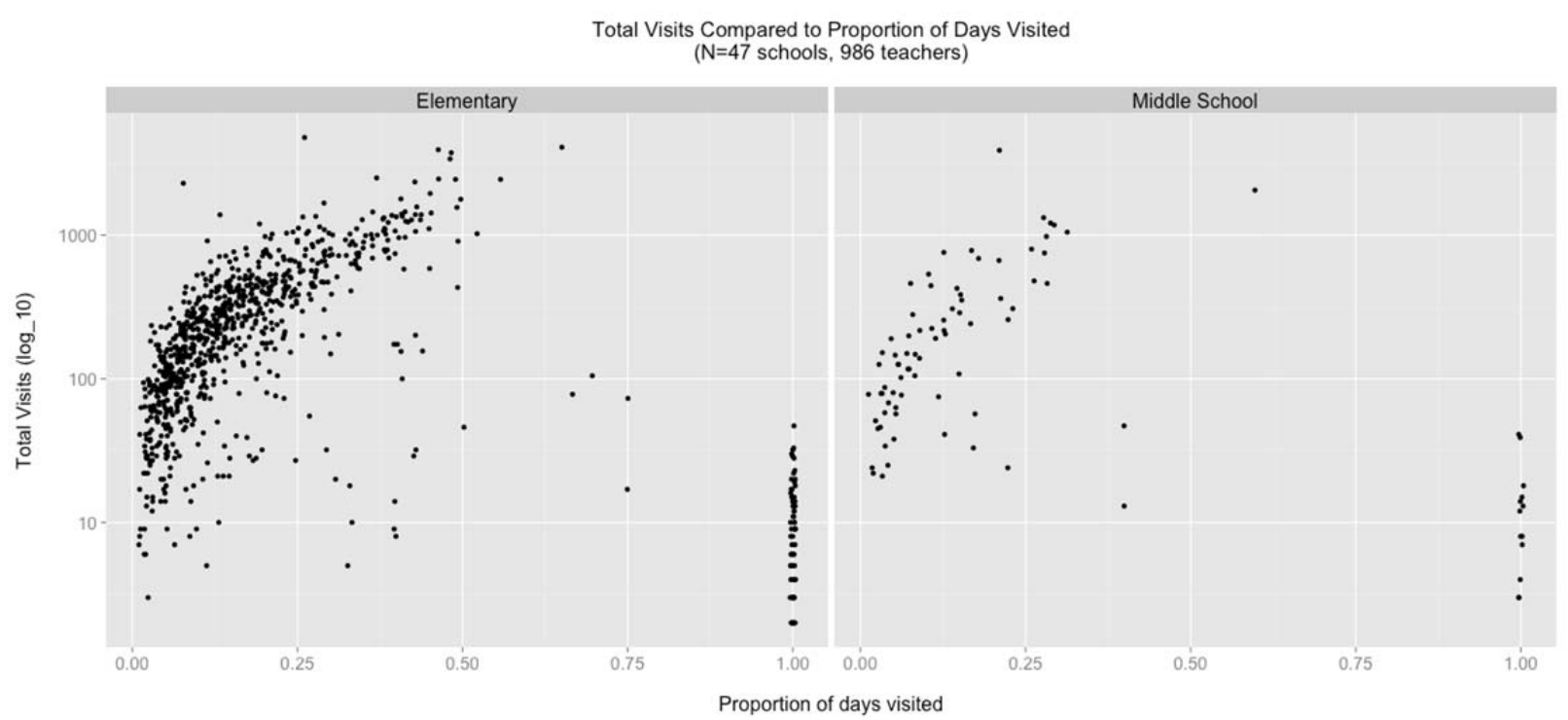

Figure 9: Total visits to the curriculum and proportion of days visited

This kind of data helps curriculum designers understand if and how often the curriculum is being used; what content is most and least used; and the dosage of 5E+I/A steps they accessed. In future, we will also be able to relate these data to student learning outcomes, both those measured by assessments embedded in the curriculum (which students can take online) and by district and state standardized assessments. For school and district administrators, this information can shed light on understanding teaching practices and design professional development to identify best teaching practices and address deficiencies in instruction.

\section{LEARNING ANALYTICS AND DATA VISUALIZATION TO SUPPORT TEACHERS AND ADMINISTRATORS}

In addition to using the LA data to help curriculum developers, we also process the LA data in ways to support the end users of the curriculum - teachers and administrators, primarily. In our research on curriculum use, we have learned that use varies depending on the role of the end user. For example, 
(2014). A Strategy for Incorporating Learning Analytics into the Design and Evaluation of a K-12 Science Curriculum. Journal of Learning Analytics, 1(2), 94-125.

teachers were more interested in their own use and their students' progress, while campus-level leaders were interested in trends across classes, and district-level administrators wanted to know about use and progress across campuses (Snodgrass Rangel, Monroy, Bell, \& Whitaker, 2013). Research also tells us, however, that educators often struggle to turn data into actionable information (Heer \& Shneiderman, 2012; Ingram, Seashore Louis, \& Schroeder, 2004; Kerr, Marsh, Ikemoto, Darilek, \& Barney, 2006; Lachat \& Smith, 2005; Wayman, 2005; Wayman et al., 2010).

Data visualization is an important tool that, in concert with strong theories, can help make sense of data (Duval, 2011). It is key, however, that the design of these visual interfaces be driven by teacher and administrator feedback. For example, several teachers with whom we have worked indicated that knowing what parts of the curriculum they had not yet used would help them know what they still needed to teach. In response, we created a heat map where colour intensity depicts the most and least used sections, with the goal of driving teacher attention to those sections. We have developed other data visualization technique, but covering all of them is beyond the scope of this paper. Here we describe three of them: timelines, heat maps, and a mastery tracker.

\subsection{Timelines}

Time-based visualizations can show when materials are accessed and for how long, as well as shifts in what science standards teachers access during a particular period of time. In this vein, timelines can be used to identify what teachers are teaching, when, and for how long. For example, one could see whether the life science standards are accessed before the physical science standards. The timelines can also shed light on the period of time, or duration, during which a teacher accesses a particular standard regularly. Pacing suggests the time elapsed between the completion of one standard and the beginning of a new one, which can help to identify standards that teachers may be overlapping or teaching at the same time (i.e., reviewing a set of standards while also introducing new standards). In the following paragraphs, we discuss two examples of the use of timelines.

The duration of instruction for the science topic entitled "3.5AB- Classifying Matter" for a sample of teachers in one school is depicted in Figure 10. Each horizontal bar corresponds to one teacher and bars are sorted by the first day they were used. The position on the X-axis represents the first time a teacher accessed that science topic, the length of the bar indicates the duration in days. The graph shows that "Classifying Matter" was introduced early in the school year and most of the teachers accessed it for about three to four weeks. There are also a few long horizontal bars (spanning almost to the end of the school year), this could be an indication of teachers reviewing certain materials after those science topics had been originally covered.

Another way to examine timelines is to explore how a teacher covered science topics throughout a given period of time. Figure 11 shows all science topics taught by one teacher. The $\mathrm{Y}$-axis corresponds to science topics and the X-axis to time in days. This teacher covered a total of 23 science topics, of which 21 belong to $3^{\text {rd }}$ grade and two to $2^{\text {nd }}$ grade, respectively. This proportion most likely suggests a $3^{\text {rd }}$ grade teacher accessing content from a lower grade for reinforcement purposes. Bar lengths can be clustered in three groups. The longest bars (five science topics), show duration of nearly the whole school year. A second cluster (three bars), shows duration between three and four months. A third cluster (five bars), shows duration between three and six weeks. The final cluster (nine bars) shows durations of approximately one week or less. 
(2014). A Strategy for Incorporating Learning Analytics into the Design and Evaluation of a K-12 Science Curriculum. Journal of Learning

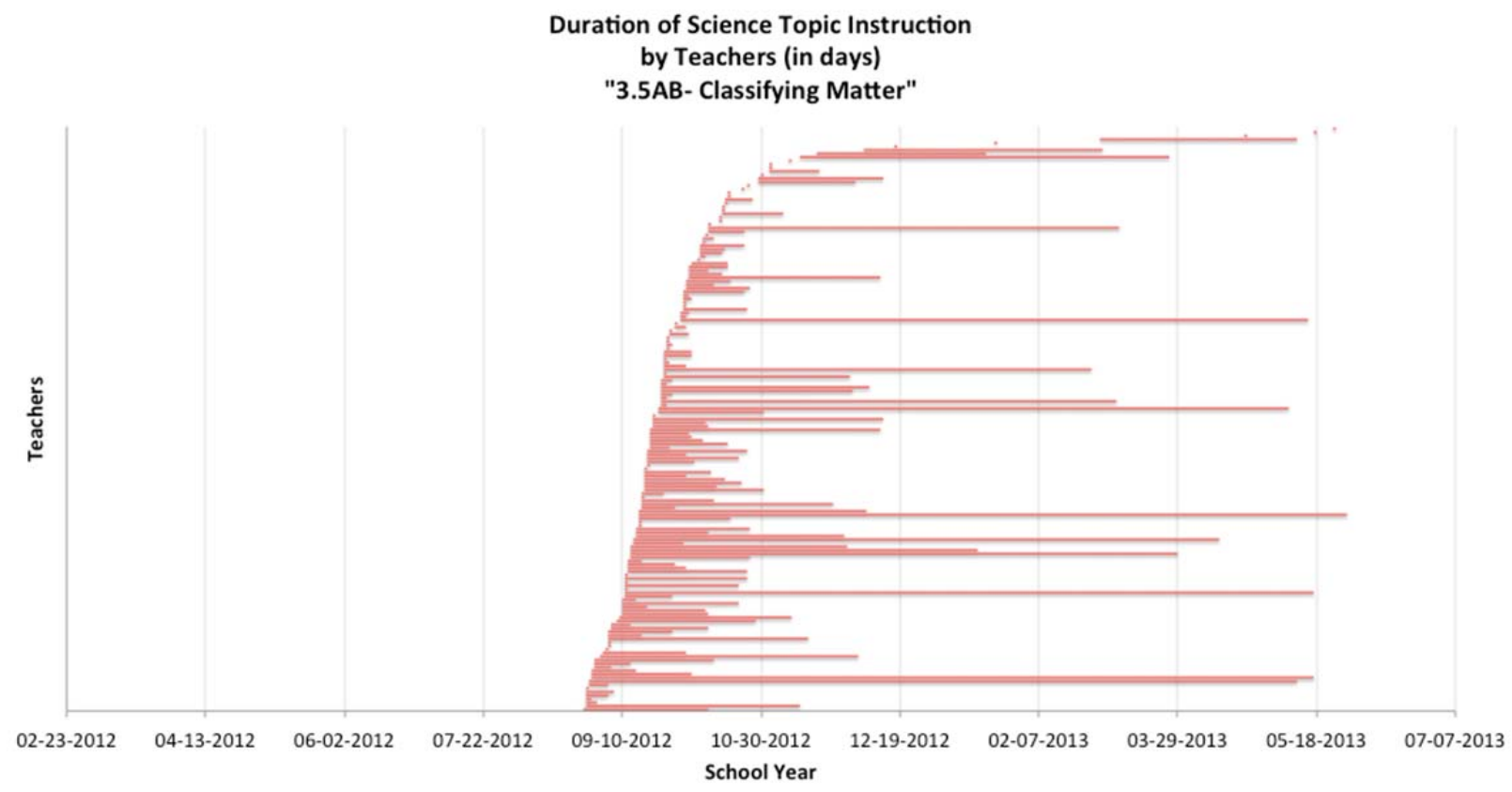

Figure 10. Timeline depicting duration of instruction for all teachers teaching the science topic entitled "3.5AB- Classifying Matter"

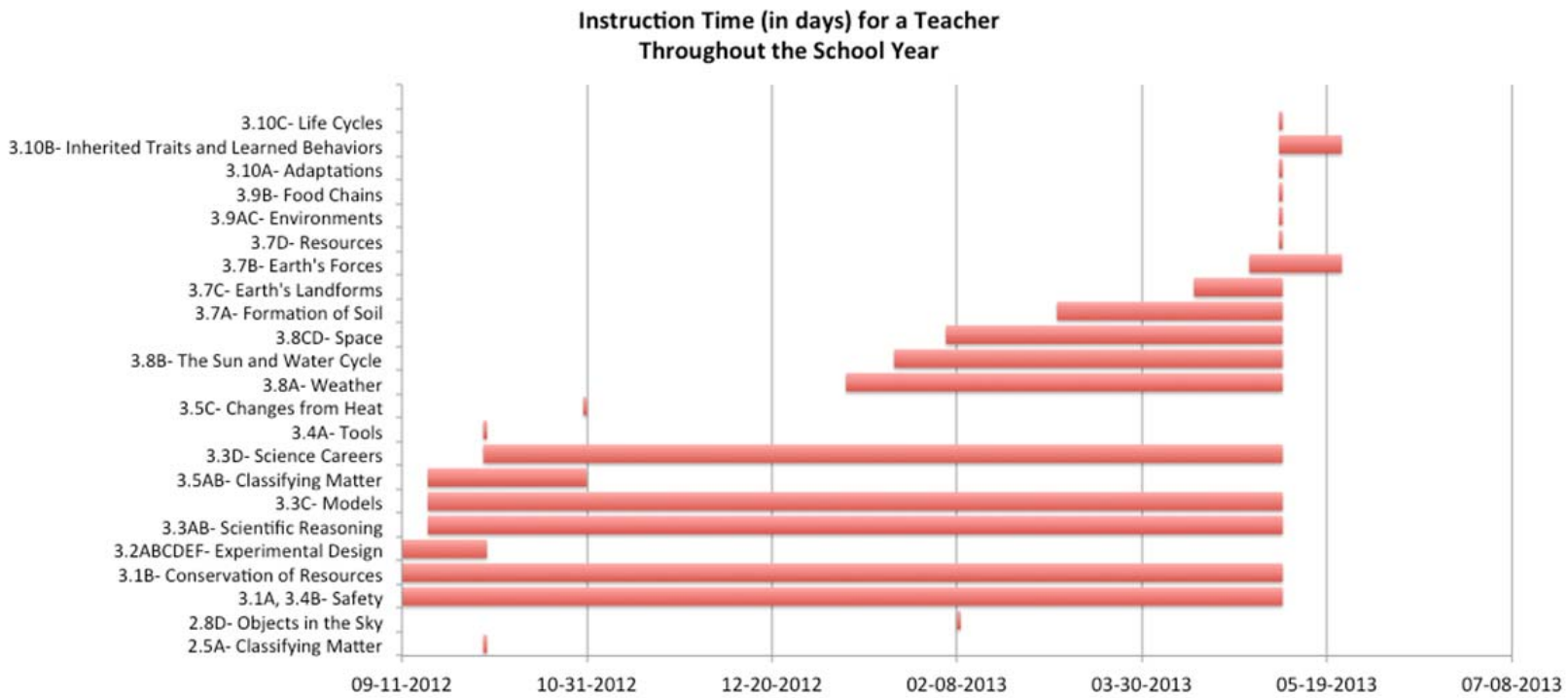

Figure 11: Timeline depicting duration of instruction of all science standards for one teacher.

\subsection{Heat maps}

Heat maps allow administrators and teachers to visualize how frequently different parts of the curriculum, including standards, steps, and activities, are accessed. Heat maps use colour or gray scale intensity to depict degrees of relationship between variables without focusing on exact values. In this 
paper we discuss two cases of heat map use for our analysis. The first example (currently available to teachers on the STEMscopes dashboard) helps to understand curriculum usage at the science topic level across the $5 \mathrm{E}+\mathrm{l} / \mathrm{A}$ steps. In the second example, heat maps are intended for school or district administrators and offer overviews of instruction dosage for the $5 \mathrm{E}+\mathrm{l} / \mathrm{A}$ steps for individual teachers at the school level. Figure 12 depicts a partial view of curriculum use for $3^{\text {rd }}$ and $4^{\text {th }}$ grades in one school district (grade level is indicated by the numeric prefix in the TEKS column). Each row corresponds to one science topic. Blank cells indicate resources not available in STEMscopes. This graph shows high use for most topics in $3^{\text {rd }}$ grade and from topics $4.5 \mathrm{~A}$ to $4.6 \mathrm{~A}$, while low use can be seen from topics $3.8 \mathrm{D}$ to 4.4A. The most used steps are Engage and Explore, while Acceleration is the least used. The most frequently used standards are "3.8CD- Space" and "4.6A- Forms of Energy." Conversely, "4.3C- Models" is the least accessed. This type of visualization offers a quick overview of what has been taught and to what degree.

\begin{tabular}{|c|c|c|c|c|c|c|c|c|c|c|c|}
\hline & & & $\leftarrow$ Less & & & More $\rightarrow$ & & & & & \\
\hline TEKS & Scope & Total & Overview & Essentials & Engage & Explore & Explain & Elaborate & Evaluate & Intervention & Acceleration \\
\hline $3.68,5.60$ & ReSTAARt Forces and Motion & 918 & 196 & 154 & 174 & ข & 105 & 81 & 111 & & \\
\hline $3.6 \mathrm{C}$ & Magnetism and Gravity & 4000 & 1000 & 523 & 000 & an & 500 & 460 & $3 n$ & 324 & 130 \\
\hline $3.7 \mathrm{~A}$ & Formation of Soll & 7000 & 1302 & $\infty$ & 1217 & $\infty$ & 1005 & 610 & $=\infty$ & 613 & 2000 \\
\hline 3.78 & Earth's Forces & $\infty 000$ & so & 14 & 21 & 20 & 15 & - & 17 & 408 & 10 \\
\hline $3.7 \mathrm{C}$ & Earth's Landtorms & 4184 & $\infty$ & 407 & 704 & $s 00$ & SO7 & 305 & 201 & 27 & 145 \\
\hline 3.70 & Resources & 1360 & 902 & 178 & 200 & 111 & in & 110 & $n$ & $\infty$ & s \\
\hline $3.8 \mathrm{~A}$ & Weather & 6000 & 1204 & $m$ & 1506 & 1002 & $n$ & s78 & 410 & 2007 & 100 \\
\hline 2.88 & The Sun and Water Cyole & $\mathrm{mm}$ & 1535 & $\infty 20$ & 1712 & 1210 & 87 & 817 & $=20$ & 850 & 240 \\
\hline $3.8 \mathrm{CD}$ & Space & 00012 & 1700 & $\infty \infty$ & 1544 & 157 & 1151 & 1007 & 000 & on & 264 \\
\hline 3.80 & RestaApt Planets & $\mathbf{\infty}+1$ & $\infty$ & $\infty$ & s4 & $\infty$ & $\infty$ & $\infty$ & $\boldsymbol{\mu}$ & & \\
\hline $39 \mathrm{~A}$ & RESTAAR: Environments & 120 & 27 & is & zs & is & is & 17 & - & & \\
\hline 3.9AC & Environments & SA1 & 102 & s4 & $\infty$ & 48 & 4 & 32 & so & $\infty$ & 18 \\
\hline 2.98 & Food Chains & 251 & $\infty$ & 10 & 70 & 22 & 57 & 30 & 20 & 24 & 2 \\
\hline $4.10 \mathrm{~A}$ & Adaptations & 345 & or & w & $n$ & si & $\approx$ & $\boldsymbol{z}$ & ж & $\infty$ & 4 \\
\hline 4.108 & Inherted Trats and Learned Behaviors & 140 & 20 & 17 & n & is & is & is & $"$ & - & - \\
\hline $4.10 \mathrm{C}$ & Lite Cycles & 125 & 24 & 16 & 19 & is & is & $"$ & 10 & - & $s$ \\
\hline 4.1A, 4.4B & Satety & 600 & $2 \pi$ & $\infty$ & so & 114 & $\infty$ & & 11 & & \\
\hline 4.18 & Conservation of Resources & 100 & $n$ & , & 16 & $n$ & 2 & & 27 & & \\
\hline 4.2ABCDEF & Expermental Design & 500 & 130 & 20 & 4 & $n$ & $\infty$ & & so & & \\
\hline 4.3AB & Sclentfic Reasoning & 250 & $\infty$ & 7 & 28 & 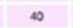 & « & & s6 & & \\
\hline $4.3 \mathrm{C}$ & Models & 61 & w & & 了 & , & - & & - & & \\
\hline 4.30 & Science Careers & 200 & n & is & $y$ & es & $\mu$ & & $\boldsymbol{x}$ & & \\
\hline $4.4 \mathrm{~A}$ & Tools & 502 & 196 & 10 & 20 & 49 & 22 & & $\infty$ & & \\
\hline 4.5A & Classilying Matter & 4000 & 1238 & 487 & 700 & 30 & $m$ & 455 & 20 & 42 & n \\
\hline 4.5B & Changes from Heat & $21 \times 0$ & sest & 200 & 400 & 276 & 970 & 271 & 200 & 100 & 51 \\
\hline $4.5 \mathrm{C}$ & Motures and Solvtions & 3180 & 000 & 200 & 40 & 202 & $m$ & 200 & 314 & 200 & $n$ \\
\hline $4.6 \mathrm{~A}$ & Forms of Energy & 60004 & 1796 & 1105 & 1654 & 900 & 1000 & 704 & $7 s$ & 616 & 178 \\
\hline
\end{tabular}

Figure 12: Heat map depicting a partial list of STEMscopes content use for one district. Science topics included are for $3^{\text {rd }}$ and $4^{\text {th }}$ grades (indicated by the numeric prefix on the TEKS column).

We then investigated whether teacher visits were evenly distributed across steps or concentrated on a specific step. Figure 13 depicts six gray-scaled heat maps for elementary schools. Each row represents one teacher and columns from left to right show total visits, percentage of visits for the most used step, and seven grayed-scaled columns indicating the proportion of visits for each of the 5E+I/A steps for that teacher. The heat map scale ranges from $0 \%$ (lighter gray) to $100 \%$ (black). Rows are sorted by total visits by teacher; hence, higher users are at the top, while lower users are at the bottom.

Approximately three-quarters of teachers in "School E1" have the Explore step as the most visited one, between $27 \%$ and $49 \%$. As the total of number of visits decreases, the most visited step varies between Elaborates and Engages. With the exceptions of teachers U_365 and U_933, access to the Acceleration and Intervention steps is extremely low. Usage in "School E2" also depicts high activity in the Explore category; however, high activity is also seen in the Elaborate step, ranging from $31 \%$ to $70 \%$ for most of 
the higher users. Usage in "School E3" indicates a more balanced proportion for the Engages and Explores sections for approximately the top nine high users; it also suggests some degree of use for the Evaluates section. In contrast to the other two schools, "School E3" shows some degree of activity for the Intervention step.

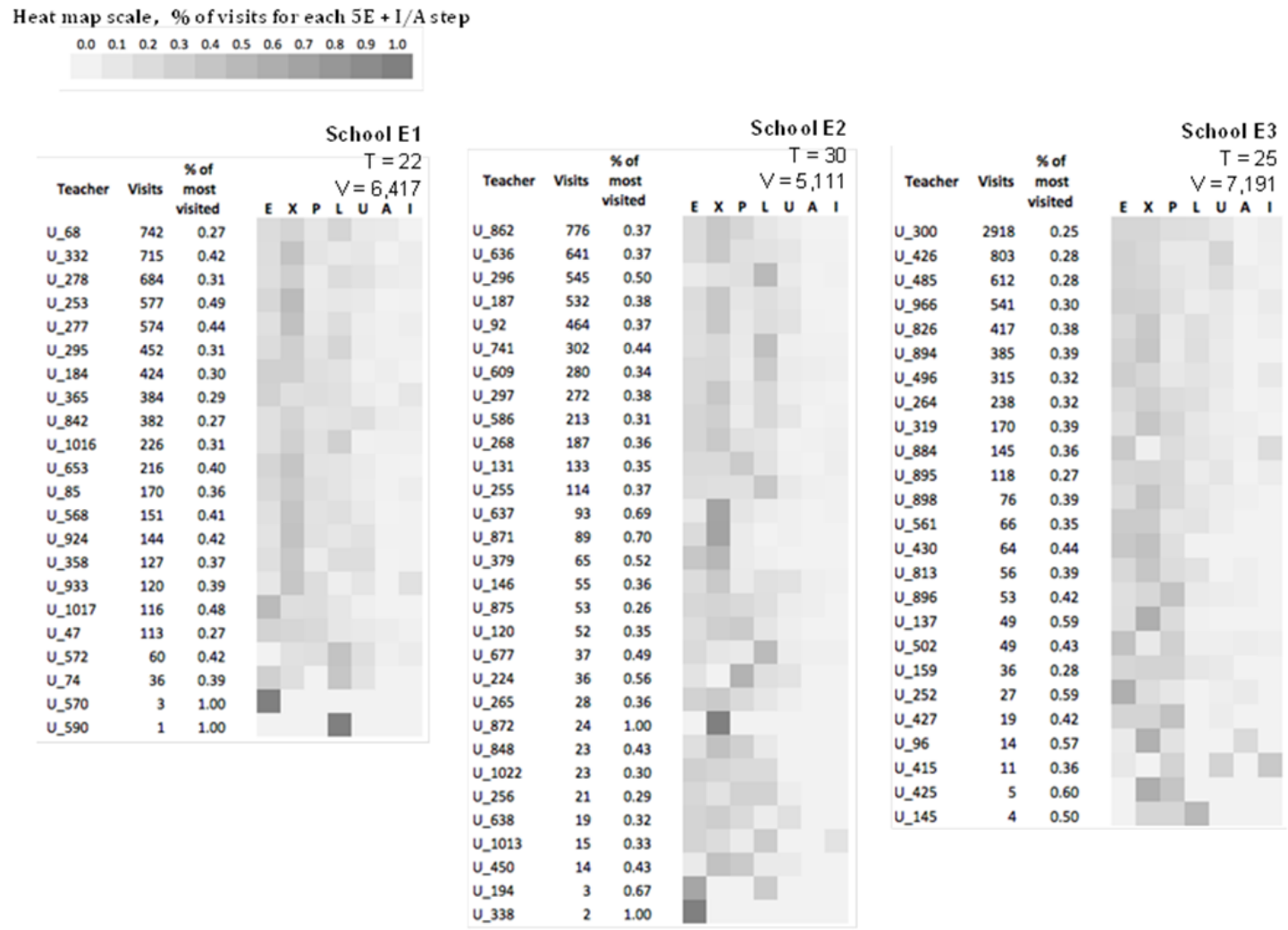

Figure 13. Heat maps depicting percentage of visits to each $5 E+1 / A$ step for teachers in three elementary schools.

Heat maps with a high concentration of cells in one or two columns would be an indication of highly skewed distributions. Therefore, the majority of heat maps show that most teachers tend to access different steps of the curriculum in a balanced way. Especially encouraging is to observe that overall the Engage, Explore, and Explain steps are evenly accessed for the highest users in the three schools. Conversely, teachers with a high concentration on one step are those located at the bottom of the graphs. Although, this is not the intended use of the curriculum, these teachers have an overall low number of visits. The low use for the Acceleration and Intervention steps can be attributed to teachers' lack of training with differentiating instruction among their students or no timely actionable information in the current dashboard, which makes it more difficult for them to identify diverse intervention levels for students.

The dosage of curriculum use for middle-school teachers shows sparser distribution and fewer teachers (see Figure 14). For instance, the highest user in "School M1," uses Evaluates the most, with $30 \%$ of usage. Darker colours on the last column indicate teachers using Intervention elements (almost half of 
teachers). Similar distribution can be seen in "School M2." Use patterns for "School M3" depict a concentration on Engage and Explore content for the top four highest users and a shift to Explain, Elaborate, and Evaluate content for the following two teachers. One exception is teacher U_789, who accessed Acceleration elements all the time.

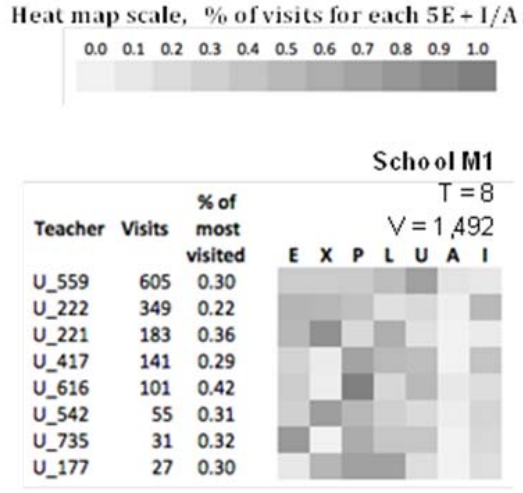

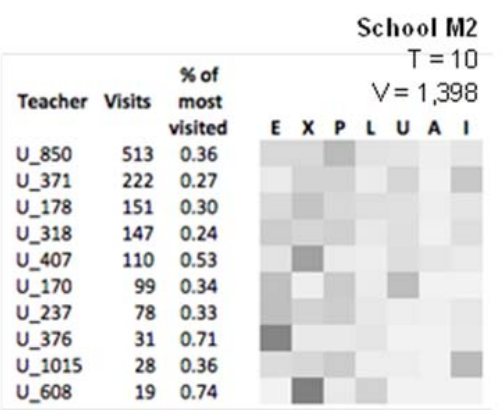

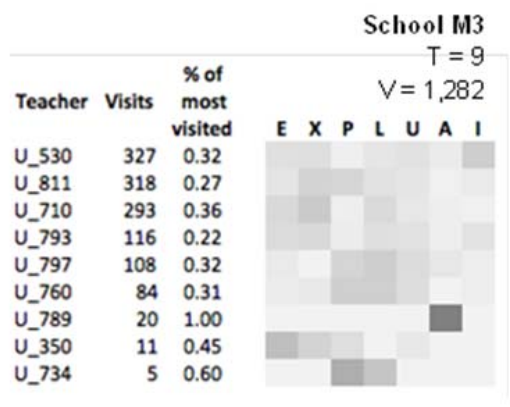

Figure 14. Heat maps depicting percentage of visits to each $5 \mathrm{E}+\mathrm{l} / \mathrm{A}$ step for teachers in three middle schools.

\subsection{Mastery trackers}

Finally, we have created a way for stakeholders to visualize student progress towards mastery of learning standards. This information is crucial for several reasons, not least of which is that in the U.S., public school students (and teachers and schools) are held accountable for their learning at the end of every school year in various subjects on mandatory state tests. The mastery tracker shown in Figure 16 below depicts whether individual students are making progress toward mastery on the required standards. ${ }^{3}$

The focus of the visualization is on progress because the mastery approach to student learning assumes that students should have more than one opportunity (or in many cases, as many opportunities as they need) to master a concept. Figure 16 shows a prototype of a dashboard with information for a class of $4^{\text {th }}$ grade students. The columns show standards grouped by area (e.g., Organism and Environments), and the upward green arrows represent an improvement in performance from the previous assessment, while the downward red arrows indicate a decline in performance from one assessment to the next. Students are clustered by degree of intervention or acceleration they require, represented by the coloured cells. Students in the intervention group (yellow-coloured cells) are the ones who, although they are making progress, need a moderate amount of support from the teacher. Those in the intensive intervention group (the pink-coloured cells) require more help because they are not making sufficient progress towards mastery. Conversely, students in the acceleration group (green-coloured cells) can be challenged with more advanced activities from the acceleration step. This dashboard can help teachers better understand individual student needs, making it easier for teachers to differentiate and even personalize their instruction.

\footnotetext{
${ }^{3}$ The definition of mastery can be set by teachers, but usually the benchmark is $80 \%$ or higher on the final
} standards-based assessment. 


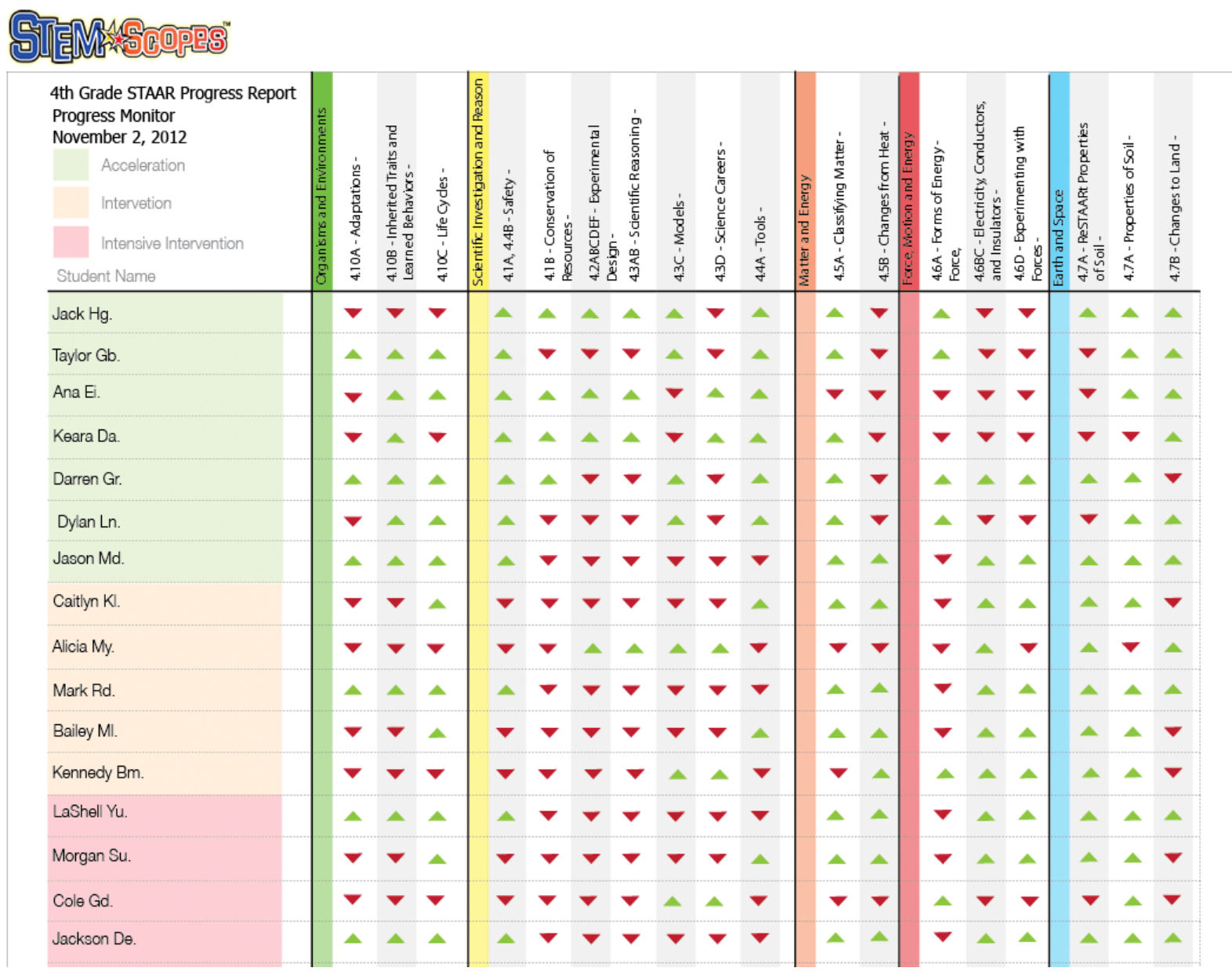

Figure 16: Dashboard prototype depicting a partial list of $4^{\text {th }}$-grade student progress for all scopes grouped by topic. Red arrows indicate grade drop from previous assessment, while green arrows show grade increase from previous assessment.

\section{HARNESSING LEARNING ANALYTICS TO MEASURE FIDELITY OF IMPLEMENTATION}

Research question 3 asks how LA data can be integrated into the evaluation of a curriculum. In this section, we discuss how we are integrating LA data into our curriculum evaluation work by using LA data as one measure of fidelity of implementation. In this section, we also detail the third prong of our LA data strategy; that is, how we pair the LA data with more traditional and qualitative data collection and analysis to create a holistic understanding of curriculum use and impact.

In order to understand the impact of the curriculum on student learning, we relate the level and kind of curriculum use to different student outcomes (Duriak \& Dupre, 2008; Song \& Herman, 2010). It is essential to understand how stakeholders are using the curriculum in order to contextualize the impact. 
(2014). A Strategy for Incorporating Learning Analytics into the Design and Evaluation of a K-12 Science Curriculum. Journal of Learning Analytics, 1(2), 94-125.

For example, if there is little use of the curriculum, then it is not possible to attribute any change in student learning to use of the curriculum; the reverse also is true. The LA data are key here because they provide a detailed and multifaceted account of curriculum use, as we described above. We utilize the LA data as a complement to more traditional forms of measuring use, which we also describe below. And while it can be difficult to scale a high-quality qualitative data collection strategy, it is difficult, if not impossible, to really understand how an online curriculum, such as STEMscopes, is being used without spending time observing its use in classrooms and talking to teachers and students about their use.

Typically, program evaluators collect data relating to the fidelity of implementation (or use) of an intervention in order to gauge the relative impact of the intervention on student learning. Dusenbury, Brannigan, Falco, and Hansen (2003) suggest that fidelity of implementation (FOI) should be measured in five ways: 1) adherence to the program; 2) dose or exposure to the program; 3) quality of program delivery; 4) participant responsiveness to the program; and 5) program differentiation (differentiation of components within the program). Other researchers have proposed different ways to conceptualize and measure FOI, but we focus on the previous five. In the rest of this section, we briefly describe how we incorporate LA specifically into evaluations, and then we discuss three other ways we collect data to measure impact.

We use LA data to measure fidelity of implementation in four of the five ways described in the previous section. First, LA data provide a measure of adherence; that is, whether a teacher or student is utilizing the curriculum in the intended way. LA data allow us to track precisely how a teacher has interacted with the program, including the proportion of inquiry instruction, as discussed in section four. Second, LA data can measure dosage, or how frequently and for how long a teacher engages with the curriculum. Third, LA data can be utilized to measure how engaged a teacher is with the curriculum by looking at, for example, time spent on a component or how quickly a teacher moves through components. Fourth, LA data can be used to measure program differentiation, or the impact of different components of the curriculum on student learning. This can be done by examining how a teacher interacts with various components, and weighing these data with other dosage data to estimate their impact on student learning outcomes, such as interim assessment scores as well as end-of-year test scores.

\subsection{Using teacher surveys to measure fidelity of implementation}

A common way to gauge teacher use of a curriculum (or other intervention) is to ask them to self-report in a survey. As part of our ongoing effort to evaluate the use and impact of the STEMscopes curriculum, in the fall of 2012 we created and administered a survey to 755 elementary school teachers in a large urban school district where some schools use the curriculum. The survey, containing 80 items, was created based on existing surveys about technology and data use. While some of the items are specific to the STEMscopes curriculum and its particular offerings, others are generalizable to other technology or curricula. The survey asks teachers about the following concepts: teacher notions of data and data use, how teachers use STEMscopes, attitudes toward STEMscopes, challenges to using STEMscopes, as well as district and school support for using STEMscopes. The survey was piloted and validated in the fall of 2012 (See Snodgrass Rangel, et al. 2013 for more information on the survey and for more detailed findings), 210 teachers responded to the survey, a response rate of $28 \%$. 
(2014). A Strategy for Incorporating Learning Analytics into the Design and Evaluation of a K-12 Science Curriculum. Journal of Learning Analytics, 1(2), 94-125.

As part of this study, and as an example of how to combine these two kinds of data, we related teacher survey responses to their LA data to see how closely they were related. Specifically, we used correlation analysis on the associations between these three variables and several user analytics variables. We also created and used four variables from the LA data we had access to at that time:

1. The number of visits to pages containing instructional content for any of the seven steps, weighted by the number of grade levels accessed by the teacher's account (continuous variable)

2. The number of visits to pages containing instructional content for any of the seven steps, weighted by the number of objectives the teacher had taught to that point (continuous variable)

3. A categorical variable (created using quartiles) measuring the un-weighted number of visits to pages containing instructional content for any of the seven steps (1=low use, 2=medium low use, 3=medium high use, 4=high use)

4. A categorical variable (created using quartiles) measuring the number of visits to pages containing instructional content for any of the seven steps, weighted by the number of grade levels accessed by the teacher's account (1=low use, $2=$ =medium low use, $3=$ medium high use, $4=$ high use).

First, we correlated teacher responses to the survey question asking how often they utilized the $5 \mathrm{E}+\mathrm{l} / \mathrm{A}$ steps in the suggested order and an analytics variable that measured how frequently teachers actually used all seven steps in the suggested order. Second, we correlated teacher responses to how often they utilized the $5 \mathrm{E}+\mathrm{l} / \mathrm{A}$ steps in the suggested order and the frequency with which teachers used the $5 \mathrm{E}$ (without the I/A) steps in the suggested order. We found that while teachers reported using the curriculum for some to most of the standards they taught, the LA data told a different story (see Table 3).

Table 3. Descriptive Statistics for Reported and Actual Use of STEMscopes

\begin{tabular}{|c|c|c|c|c|}
\hline & & Mean & SD & Range \\
\hline \multicolumn{5}{|l|}{ Reported Use } \\
\hline & Average use of teacher components & 2.70 & 0.76 & $1.00-4.00$ \\
\hline & Average use of $5 \mathrm{E}+\mathrm{l} / \mathrm{A}$ steps & 2.48 & 0.64 & $1.00-4.00$ \\
\hline & $\begin{array}{r}\text { Average use of } 5 \mathrm{E}+1 / \mathrm{A} \text { steps and components in } \\
\text { order }\end{array}$ & 2.62 & 0.60 & $1.00-4.00$ \\
\hline \multicolumn{5}{|l|}{ Actual Use } \\
\hline & $\begin{array}{r}\text { Number of 5E visits weighted by number of grades } \\
\text { taught }\end{array}$ & 103.42 & 125.84 & $1.00-1084.00$ \\
\hline & $\begin{array}{r}\text { Number of 5E visits weighted by number of } \\
\text { objectives taught }\end{array}$ & 20.09 & 13.36 & $2.00-75.00$ \\
\hline & $\begin{array}{r}\text { Average number of visits to } 5 \mathrm{E}+\mathrm{l} / \mathrm{A} \text { steps } \\
\text { (categorical) }\end{array}$ & 2.49 & 1.13 & $1.00-4.00$ \\
\hline & $\begin{array}{r}\text { Average visits to } 5 \mathrm{E}+\mathrm{l} / \mathrm{A} \text { steps, weighted by number } \\
\text { of grades taught (categorical) }\end{array}$ & 2.24 & 0.83 & $1.00-4.00$ \\
\hline
\end{tabular}


(2014). A Strategy for Incorporating Learning Analytics into the Design and Evaluation of a K-12 Science Curriculum. Journal of Learning Analytics, 1(2), 94-125.

In the correlation analyses, we found that while almost all of the correlations were positive, very few were statistically significant relationships. The two that were significantly (but weakly) related were between the categorical variable measuring the average number of visits to a page containing instructional content from any of the seven steps ( $1=$ low use, $4=$ high use) and the reported average use of teacher components $(r(114)=0.195, p<0.05)$, and the reported combined average use of the teacher components, the $5 \mathrm{E}+\mathrm{l} / \mathrm{A}$ steps, and the frequency with which a teacher uses the steps in the appropriate sequence $(r(114)=0.219, p<0.05)$. The results of the correlation analysis can be found in Table 4 below.

Table 4. Results of correlation analysis for reported and actual use

\begin{tabular}{|c|c|c|c|c|}
\hline User analytics & & $\begin{array}{r}\text { Reported average } \\
\text { use of teacher } \\
\text { components }\end{array}$ & $\begin{array}{r}\text { Reported } \\
\text { average use of } \\
5 E+1 / A \text { steps }\end{array}$ & $\begin{array}{r}\text { Average use of } \\
5 \mathrm{E}+\mathrm{l} / \mathrm{A} \text { steps and } \\
\text { components in } \\
\text { order }\end{array}$ \\
\hline \multirow{2}{*}{$\begin{array}{l}\text { Number of } 5 E \text { visits weighted by } \\
\text { number of grades taught ( } \mathrm{N}=114)\end{array}$} & Pearson Correlation & 0.160 & 0.030 & 0.140 \\
\hline & Sig. (2-tailed) & 0.090 & 0.780 & 0.130 \\
\hline \multirow{2}{*}{$\begin{array}{l}\text { Number of } 5 E \text { visits weighted by } \\
\text { number of objectives taught }(\mathrm{N}=114)\end{array}$} & Pearson Correlation & 0.090 & -0.050 & 0.060 \\
\hline & Sig. (2-tailed) & 0.330 & 0.570 & 0.560 \\
\hline \multirow{2}{*}{$\begin{array}{r}\text { Average number of visits to } 5 \mathrm{E}+\mathrm{l} / \mathrm{A} \\
\text { steps (categorical) }(\mathrm{N}=114)\end{array}$} & Pearson Correlation & $0.195^{*}$ & 0.140 & $0.219^{*}$ \\
\hline & Sig. (2-tailed) & 0.040 & 0.140 & 0.020 \\
\hline \multirow{2}{*}{$\begin{array}{r}\text { Average visits to } 5 \mathrm{E}+\mathrm{l} / \mathrm{A} \text { steps, weighted } \\
\text { by number of grades taught } \\
\text { (categorical) }(\mathrm{N}=113)\end{array}$} & Pearson Correlation & 0.060 & -0.040 & 0.030 \\
\hline & Sig. (2-tailed) & 0.550 & 0.710 & 0.730 \\
\hline
\end{tabular}

* Correlation is significant at the 0.05 level (2-tailed)

We also correlated teacher survey responses about how frequently they use the 5E+1/A steps in the suggested order with the frequency with which they actually used all of the 5E+I/A steps in the suggested order (based on the data analytics). The results showed no significant association between a teacher's reported use and actual use of the 5E+I/A steps in the suggested order $(r(111)=-0.02, p=$ 0.84). Second, we conducted a correlation between teacher survey responses about how frequently they use the $5 \mathrm{E}+\mathrm{l} / \mathrm{A}$ steps in the suggested order with the frequency that they actually used just the steps in the suggested order. The results showed no significant association between a teacher's reported use and actual use of the $5 \mathrm{E}$ steps in the suggested order $(r(111)=0.02, p=0.83)$. In other words, there appeared to be no relationship between perceived and actual use regarding the $5 \mathrm{E}+\mathrm{l} / \mathrm{A}$ steps in the order intended by the curriculum designers.

The question that these two analyses raise, of course, is which measure of teacher use is correct? The answer we have settled on is that neither is "wrong" or "right," and that therefore they must be used jointly to piece together a balanced picture of teacher use. In other words, data from different sources must be triangulated. In the next two sections, we describe two more ways to collect data for the purpose of creating a more nuanced picture of curriculum use. 
(2014). A Strategy for Incorporating Learning Analytics into the Design and Evaluation of a K-12 Science Curriculum. Journal of Learning Analytics, 1(2), 94-125.

\subsection{Using teacher focus groups and interviews to measure fidelity of implementation}

The research team also conducted teacher focus groups to understand how teachers use the curriculum. The benefit of conducting focus groups is that we are able to engage directly with teachers and ask them about their use of the curriculum. We can follow up on their answers and probe more deeply for explanations of certain behaviours. In this way, we can look at data based on access to the curriculum next to data on what the teachers do once they have accessed the curriculum and are in their classrooms teaching students.

The focus groups we conducted were separate from the external evaluation discussed in previous sections. Instead, they have been part of internal research efforts. For example, in the fall of 2012, the research team asked the principals at two schools that use STEMscopes to put together a group of 3-5 teachers to meet with us. A total of 11 teachers participated (see Table 5). Of these teachers, all but two were self-contained teachers who taught science in addition to other subject areas. Of the 11 teachers, three were novices (first year), one had medium experience (2-5 years), four were advanced (6-20 years), and four were veterans ( $21+$ years).

Table 5. Description of focus group participants

\begin{tabular}{cccccccc}
\hline Total teachers & Science only & $\begin{array}{c}\text { Grades } \\
\text { K-2 }\end{array}$ & $\begin{array}{c}\text { Grades } \\
\mathbf{3 - 5}\end{array}$ & $\begin{array}{c}\text { Novice } \\
\text { teacher }\end{array}$ & $\begin{array}{c}\text { Medium } \\
\text { experienced }\end{array}$ & $\begin{array}{c}\text { Advanced } \\
\text { teacher }\end{array}$ & $\begin{array}{c}\text { Veteran } \\
\text { teacher }\end{array}$ \\
\hline 11 & 2 & 9 & 2 & 3 & 1 & 4 & 4 \\
\hline
\end{tabular}

The team created an interview protocol to guide the focus group. The interviews were semi-structured, which allowed the conversation to develop organically. The protocol asked teachers how they felt about teaching science, using technology, using STEMscopes, and what challenges they faced when using STEMscopes to teach science. Here, we only share a few findings as they relate to use of the curriculum with the intent of demonstrating the type of findings that can be extracted from direct conversations with the curriculum's stakeholders.

\subsubsection{Uses of STEMscopes by teachers in grades $K-2$}

The majority of participating teachers were $\mathrm{K}-2$, self-contained teachers. Though all of the teachers were very positive about science and reported enjoying teaching science, it was clear that they had very little time to teach science, and so their use of STEMscopes and other science resources was quite limited. According to the teachers, they were only able to teach science two to three times a week, and this relatively short time was split between hands-on experience, such as an experiment, and science vocabulary. In fact, we specifically asked the teachers how often they were able to do science; they reported that they were working on a hands-on experience with their students almost every week.

Vocabulary, however, was the most frequently mentioned use of the curriculum; the kindergartners draw pictures of science concepts and the second graders make vocabulary cards with pictures, labels, and definitions. ${ }^{4}$ STEMscopes' vocabulary materials were particularly helpful for the bilingual teachers,

\footnotetext{
${ }^{4}$ Most frequently mentioned does not necessarily mean the most frequently used. The analytics data suggest that $\mathrm{K}-2$ teachers access the Explore step the most, indicating they do hands-on activities with their students.
} 
(2014). A Strategy for Incorporating Learning Analytics into the Design and Evaluation of a K-12 Science Curriculum. Journal of Learning Analytics, 1(2), 94-125.

most of whom teach science as an English as a Second Language (ESL) class where the focus is as much on learning English as it is on learning content. Also included in the discussion was the use of science to teach literacy. The teachers described spending most of their time on math and literacy to prepare students for the $3^{\text {rd }}$ grade state tests, and so science often became another way to work on literacy. A teacher from one school told us how her students read science stories, saying, "this week... there is a story about plants, so then you know they are identifying roots, petals, and stems, all that stuff." Other teachers described how the students kept science journals where they pasted in passages and diagrams to practice new vocabulary.

\subsubsection{Uses of STEMscopes by teachers in grades 3-5}

Teachers in the upper-elementary grades (particularly $5^{\text {th }}$ grade) had more time for science instruction, often more than an hour a day, which allowed them to utilize more parts of the curriculum. However, the teachers still expressed the need for more time to cover all of the material and review material from previous grades, where students often receive little science instruction. One of the teachers described how she strives to use all of the options contained within the curriculum, saying, "I wouldn't say [I use it] to its maximum but I would say as close as I can possibly get within the given timeframe that I am allotted."

These two teachers indicated that they try to follow the curriculum closely by doing one "E" step on each day and using as many of the assessments as they have time for. One teacher confided that, "I don't use every experiment that you guys [have]...I use most of them though, but I try to make sure that I, we do an experiment [from STEMscopes] every Tuesday and then I try to do one on Wednesdays also, I try two days of complete experiments." In this way, the teacher generally is able to meet the student needs for hands-on learning and intervention at the end of the week for those students who did not demonstrate mastery on the post-assessment. Both of the teachers also told us that, for the most part, they complete each of the 5E steps in order, though one of the teachers told us that she begins each new unit with direct instruction and note-taking. Our observations of both classrooms confirmed that both teachers begin units with direct instruction and note-taking.

Finally, the teachers rely primarily on STEMscopes for their actual lessons while following the district's scope and sequence, which directs them to teach the standards in a certain order. One of the teachers told us how she reconciles using a curriculum not officially adopted by the district: "I just read the teacher background and I just make sure that I am teaching in the sequence that [the district] is giving me to teach... I use the teacher background and all the activities from STEMscopes."

\subsection{Using classroom observations to measure fidelity of implementation}

Through classroom observations, we have seen how teachers and students interact - and do not interact - with the online curriculum. Observations, though time-consuming, are important because they allow for comparing and classifying interactions. Teachers often unwittingly over-report how often they use the curriculum, and observations can cut through the problems of self-reporting and perception.

In that same internal evaluation, we observed two teachers at different schools as they taught science. Each of the teachers we observed taught science only and was a very experienced teacher. One of them taught science to grades $3-5$, while the other only taught $5^{\text {th }}$ grade science. The teacher who taught $3^{\text {rd }}-$ 
(2014). A Strategy for Incorporating Learning Analytics into the Design and Evaluation of a K-12 Science Curriculum. Journal of Learning Analytics, 1(2), 94-125.

$5^{\text {th }}$ grade science had 18 years of experience as a teacher and instructional coach (though not in science), and this was his/her first year teaching science only. Furthermore, his/her previous teaching experience was in $1^{\text {st }}$ grade. This teacher also helps to translate curriculum for STEMscopes into Spanish, making him/her very familiar with the curriculum. The other teacher had taught for 22 years, nine of them as a science teacher exclusively. This teacher also had previous experience teaching middle-school math. During the classroom observations, we took extensive field notes, which we later coded using an observation protocol created for science classrooms. Based on these notes, we created long and detailed "inquiry profiles" that described how teachers used the curriculum and level of inquiry in each teacher's classroom. Here, we report only general findings.

We learned a great deal about the context and quality of implementation from the observations. For instance, we noted that in these classrooms, there were no more than two computers available to students, and the teachers either printed materials from the website, or projected the website onto a whiteboard. This finding can help explain variation in teacher use - some teachers may have more technology available to them than these teachers did. Similarly, we observed that while some teachers followed the curriculum very carefully, others used fewer of the activities and instead incorporated other available resources, and others still utilized the steps and activities out of the intended order. In short, the observations reveal "the face" behind the "clicks" that LA data show us.

\section{CONCLUSIONS AND FUTURE WORK}

LA has the potential to bring important changes to $\mathrm{K}-12$ education research and development if implemented with a pedagogically sound, mixed methods strategy, such as the one described in this paper. Incorporating the LA data into our ongoing research on curriculum has enabled us to dig deeply into patterns of use and to ask nuanced questions that relate to the pedagogy underpinning the curriculum and its effectiveness. We have also learned that on their own, LA data paints an incomplete picture of what teachers do in their classrooms with the curriculum. By bringing in more traditional measures of use, such as surveys, interviews, and classroom observation, we were able to contextualize some of the findings gleaned from the LA data.

As we have improved our technical capacity to work with the LA data, we have also created new ways to make the data accessible to the curriculum's key stakeholders, namely teachers and administrators. Data visualization has been the most powerful tool we have put into practice so far to translate data into information, and future work will examine the utility of these tools as well as develop new tools based on feedback.

There also are several hurdles that must be overcome to ensure that these new data collection and analysis tools do, in fact, fulfill their promise. First, schools and districts must address the gap in access to technology. While some schools have achieved one-to-one computing, most schools are not even close to this goal, and this has profound implications for our ability to collect reliable analytics data. Our conversations with and observations of teachers revealed that teachers and students often share accounts, and that students are limited in the activities they can complete online. This, in turn, means that the analytics data we collect may not be reliable: for some teachers the usage analytics may accurately portray their use, while for others, they may not. 
(2014). A Strategy for Incorporating Learning Analytics into the Design and Evaluation of a K-12 Science Curriculum. Journal of Learning Analytics, 1(2), 94-125.

A second and equally important challenge is time. Teachers often do not have time to incorporate technology and online activities into their regular instruction. It is time-consuming to plan for this incorporation, especially because it often requires the teacher to learn new software or strategies, and because it requires the teacher to create new classroom and management routines. The result of this hurdle is that the computer systems that should be collecting analytics data are not fully implemented - or are not implemented at all, which degrades the quality of data we can collect.

In our future work, we will include curriculum elements in each of the $5 \mathrm{E}+\mathrm{l} / \mathrm{A}$ steps and investigate the effects of the characteristics and properties of those elements in curriculum use. Similarly, we will disaggregate use by science standard, skills, and concepts covered on each curriculum step. These new scenarios will offer a deeper and richer picture of science teaching and learning in the $\mathrm{K}-12 \mathrm{realm}$. We will conduct studies to investigate sequences of visits, pacing, and patterns of use at different points in time. This in turn will help us to answer questions related to curriculum use changes throughout the school year and consistency of use across science standards, schools, and districts, with implications for targeted professional development for teachers and curriculum design. We will also examine specific use patterns and relate them to student learning outcomes. These, no doubt, will present the team with fresh challenges as some components of the curriculum may turn out to be more effective than others, and these results may confound the relationships we hypothesize to exist.

Though not a panacea for the challenges facing K-12, a strong LA data strategy can help researchers and educators alike make sense of the large amounts of data generated by the increased use of mobile devices, computers, and other technology in classrooms. With an improved understanding of data, students can learn from their own mistakes. Teachers can improve their lessons, work with students who need extra help, and provide extensions for those ready to move on. Analysts can improve the curriculum and the resources available to teachers and students. The strategy described in this paper was developed to analyze detailed usage patterns of the online science curriculum, STEMscopes. This approach enables analysis of large amounts of data and opens the possibilities to complex undertakings such as the creation of personalized learning environments.

\section{ACKNOWLEDGMENTS}

We would like to thank the STEMscopes production team for their work on the science curriculum. Specials thanks go to the teachers and science specialists who participated in our focus groups. Thanks also go to Amber Muscarello for her expertise on curriculum design and science teaching. Her contribution helped in the interpretation of the analytics data. Thanks to Dr. Elizabeth Bell who helped with the survey data. Finally, thanks to Dan Hoyt for reviewing this manuscript.

\section{REFERENCES}

Arnold, K. (2010). Signals: Applying academic analytics. EDUCAUSE Quarterly, 33(1).

Atkinson, M., \& Wiley, D. (2011). Learning analytics as interpretive practice: Applying Westerman to educational intervention. Proceedings of the First International Conference on Learning Analytics and Knowledge, Banff, Alberta, Canada, February 17-March 1, 2011, 117-121.

Baker, S., \& Yacef, K. (2009). The state of educational data mining in 2009: A review and future versions. Journal of Educational Data Mining, 1(1), 3-17. 
(2014). A Strategy for Incorporating Learning Analytics into the Design and Evaluation of a K-12 Science Curriculum. Journal of Learning Analytics, 1(2), 94-125.

Beck, J., \& Mostow, J. (2008). How who should practice: Using learning decomposition to evaluate the efficacy of different types of practice for different types of students. Intelligent Tutoring Systems, Lecture Notes in Computer Science. Berlin/Heidelberg: Springer, 435-362.

Bybee, R., Taylor, J., Gardner, A., Van Scotter, P., Powell, J., Westbrook, A., \& Landes, N. (2006). The BSCS 5E instructional model: Origins, effectiveness, and applications. Retrieved from http://bscs.org/sites/default/files/_legacy/BSCS_5E_Instructional_ModelExecutive_Summary_0.pdf

Campbell, J., \& Oblinger, D. (2007). Academic analytics. EDUCAUSE Review, 42(4), 40-57.

Cho, V., \& Wayman, J. (2014). Districts' efforts for data use and computer data systems: The role of sensemaking in system use and implementation. Teachers College Record Volume, 116(2), ID Number: 17349.

Crawford, B. (2000). Embracing the essences of inquiry: New roles for science teachers. Journal of Research in Science Teaching, 37(9), 916-937.

Culatta, R. (2012). From innovation clusters to datapalooza: Accelerating innovation in educational technology. Retrieved from http://www.educause.edu/ero/article/innovation-clustersdatapalooza-accelerating-innovation-educational-technology

DeSantis, N. (2012). A boom time for education start-ups: Despite recession investors see technology companies' "internet moment." The Chronicle of Higher Education. Retrieved from http://chronicle.com/article/A-Boom-Time-for-Education/131229/.

Duriak, J. A., \& Dupre, E. P. (2008). Implementation matters: A review of research on the influence of implementation on program outcomes and the factors affecting implementation. American Journal of Community Psychology, 41, 327-349.

Dusenbury, L., Brannigan, R., Falco, M., \& Hansen, W. B. (2003). A review of research on fidelity of implementation: Implications for drug abuse prevention in school settings. Health Education Research: Theory \& Practice, 18(2), 237-256.

Duval, E. (2011). Attention please! Learning analytics for visualization and recommendation. Proceedings of the First International Conference on Learning Analytics and Knowledge, Banff, Alberta, Canada, February 17-March 1, 2011, 9-17.

Elias, T. (2011). Learning analytics: Definitions, processes, and potential. Retrieved from http://learninganalytics.net/LearningAnalyticsDefinitionsProcessesPotential.pdf

Farzan, R. (2004). Adaptive socio-recommender system for open-corpus e-learning. Doctoral Consortium of the Third International Conference on Adaptive Hypermedia and Adaptive Web-Based Systems. Retrieved from http://people.cs.pitt.edu/ rosta/docs/PDF/AH2004DC.pdf

First International Conference on Learning Analytics and Knowledge (2011). https://tekri.athabascau.ca/analytics/

Ha, S., Bae, S., \& Park, S. (2000). Web mining for distance education. Proceedings of the IEEE International Conference on Management of Innovation and Technology, Singapore, November 12-15, 715-719. 
(2014). A Strategy for Incorporating Learning Analytics into the Design and Evaluation of a K-12 Science Curriculum. Journal of Learning Analytics, 1(2), 94-125.

Hamalainen, W., Suhonen, J., Sutinen, E., \& Toivonen, H. (2004). Data mining in personalizing distance education courses. Proceedings of the World Conference on Open Learning and Distance Education. Retrieved from http://www.cs.joensuu.fi/ whamalai/articles/icde_v2.pdf

Haury, D. L. (1993). Teaching Science through Inquiry with Archived Data. ERIC Digest. (EDO-SE-01-1). Columbus, OH: ERIC Clearinghouse for Science, Mathematics, and Environmental, Education. Retrieved from http://www.gpo.gov/fdsys/pkg/ERIC-ED465545/pdf/ERIC-ED465545.pdf

Heer, J., \& Shneiderman, B. (2012). Interactive dynamics for visual analysis. Communications of the ACM, 55(4), 45-54.

Hendricks, M., Plantz, M., \& Pritchard, K. (2008). Measuring outcomes of United Way-funded programs:

Expectations and reality. In J. G. Carman \& K. A. Fredericks (Eds.), New Directions for Evaluation, Hoboken, NJ: Wiley, pp. 13-35.

Heraud, J., France, L., \& Mille, A. (2004). Pixed: An ITS that guides students with the help of learners' interaction log. 7th International Conference on Intelligent Tutoring Systems, 57-64. Retrieved from http://citeseerx.ist.psu.edu/viewdoc/download?doi=10.1.1.94.4987\&rep=rep1\&type=pdf

Hew, F., \& Brush, T. (2007). Integrating technology into K-12 teaching and learning: Current knowledge gaps and recommendations for future research. Educational Technology Research and Development, 55, 223-252.

Ingram, D., Seashore Louis, K., \& Schroeder, R. (2004). Accountability policies and teacher decision making: Barriers to the use of data to improve practice. Teachers College Record, 106(6), 12581287.

Jagadish, H. (2012, May 5). Big data: It's not just the analytics. Message posted to http://wp.sigmod.org/?p=430.

Junco, R. (2012, October 28). Most ed-tech startups suck! Here's where they go wrong. Message posted to http://venturebeat.com/2012/10/28/most-ed-tech-startups-suck-heres-where-theyre-goingwrong/.

Keengwe, J., Onchwari, G., \& Wachira, P. (2008). Computer technology integration and student learning: Barriers and promise. Journal of Science Education and Technology, 17(6), 560-565.

Kerr, K. A., Marsh, J. A., Ikemoto, G. S., Darilek, H., \& Barney, H. (2006). Strategies to promote data use for instructional improvement: Actions, outcomes, and lessons from three urban districts. American Journal of Education, 112(4), 496-520.

Keys, C., \& Bryan, L. A. (2001). Co-constructing inquiry-based science with teachers: Essential research for lasting reform. Journal of Research in Science Teaching, 38, 631-645.

Koehler, M. J., \& Mishra, P. (2005). What happens when teachers design educational technology? The development of technological pedagogical content knowledge. Journal of Educational Computing Research, 32(2), 131-152.

Lachat, M., \& Smith, S. (2005). Practices that support data use in urban high schools. Journal of Education for Students Placed at Risk. 10(3), 333-349.

Lawless, K. A., \& Pellegrino, J. W. (2007). Professional development in integrating technology into teaching and learning: Knowns, unknowns, and ways to pursue better questions and answers. Review of Educational Research, 77, 575-614. 
(2014). A Strategy for Incorporating Learning Analytics into the Design and Evaluation of a K-12 Science Curriculum. Journal of Learning Analytics, 1(2), 94-125.

Leonardi, P. M. (2009). Crossing the implementation line: The mutual constitution of technology and organizing across development and use activities. Communication Theory, 19, 278-310.

Long, P., \& Siemens G. (2011). Penetrating the fog: Analytics in learning and education. EDUCAUSE Review. Retrieved from http://www.educause.edu/ero/article/penetrating-fog-analyticslearning-and-education

Lu, J. (2004). Personalized e-learning material recommender system. Proceedings of the International Conference on Information Technology for Application, Sydney, Australia, January 9-11, 374379.

Mazza, R., \& Dimitrova, V. (2004). Visualising student tracking data to support instructors in web-based distance education. Proceedings of the $13^{\text {th }}$ International World Wide Web Conference, Alternate Track Papers \& Posters, New York, May 17-22, 154-161.

Means, B., Padilla, C., \& Gallagher, L. (2010). Use of education data at the local level: From accountability to instructional improvement. Washington, DC: U.S. Department of Education, Office of Planning, Evaluation and Policy Development. Retrieved from http://www2.ed.gov/rschstat/eval/tech/use-of-education-data/use-of-education-data.pdf

Merceron, A., \& Yacef, K. (2005). TADA-Ed for educational data mining. Interactive Multimedia Electronic Journal of Computer-Enhanced Learning, 7(1), 267-287. Retrieved from http://imej.wfu.edu/articles/2005/1/03/index.asp

Minner, D. D., Levy, A. J., \& Century, J. (2010). Inquiry-based science instruction: What is it and does it matter? Results from a research synthesis years 1984 to 2002. Journal of Research in Science Teaching, 47(4), 474-496.

Monroy, C., Snodgrass Rangel, V., \& Whitaker, R. (2013). STEMscopes: Contextualizing learning analytics in a K-12 science curriculum. Proceedings of the Third International Conference on Learning Analytics and Knowledge, Leuven, Belgium, April 8-12, 210-219.

Norris, D., Baer, L., Leonard, J., Pugliese, L., \& Lefrere, P. (2008). Action analytics: Measuring and improving performance that matters in higher education. EDUCAUSE Review, 43(1), 42-67.

Orlikowski, W. J. (2000). Using technology and constituting structures: A practice lens for studying technology in organizations. Organization Science, 11(4), 404-428.

Pahl, C. (2004). Data mining technology for the evaluation of learning content interaction. International Journal on E-Learning, 3(4), 47-63.

Pardo, A., \& Delgado, C. (2011). Stepping out of the box: Towards analytics outside the learning management system. Proceedings of the First International Conference on Learning Analytics, Banff, Alberta, Canada, February 27-March 1, 163-167.

Pavlik, P., Cen, H., \& Koedinger, K. (2009). Learning factors transfer analysis: Using learning curve analysis to automatically generate domain models. Proceedings of the Second International Conference on Educational Data Mining, Cordoba, Spain, July 1-3, 121-130.

Pavlo, A., Paulson, E., \& Rasin, A. (2009). A comparison of approaches to large-scale data analysis. Proceedings of the 2009 ACM SIGMOD International Conference on Management of Data, Providence, Rhode Island, USA, June 29-July 2, 165-178. 
(2014). A Strategy for Incorporating Learning Analytics into the Design and Evaluation of a K-12 Science Curriculum. Journal of Learning Analytics, 1(2), 94-125.

Romero, C., \& Ventura, S. (2010). Educational data mining: A review of the state of the art. IEEE Transactions on Systems, Man and Cybernetics, Part C: Applications and Reviews, 40(6), 601618.

Siemens, G. (2012). Learning analytics: Envisioning a research discipline and a domain of practice. Proceedings of the Second International Conference on Learning Analytics and Knowledge, Vancouver, Canada, April 29-May 2, 4-8.

Snodgrass Rangel, V., Monroy, C., \& Whitaker, R. (2013). Teacher-centered design: Improving a K-12 science curriculum and its dashboard. Proceedings of the 2013 National Association for Research in Science Teaching, NARST Conference. Puerto Rico, April 2013.

Song, M., \& Herman, R. (2010). Critical issues and common pitfalls in designing and conducting impact studies in education: Lessons learned from the What Works Clearinghouse (Phase I). Educational Evaluation and Policy Analysis, 32(3), 351-371.

Suthers, D., Ravi, V., Medina, R., Joseph, S., \& Dwyer, N. (2008). Beyond threaded discussion: Representational guidance in asynchronous collaborative learning environments. Computers \& Education, 50(4), 1103-1127.

Talavera, L., \& Gaudioso, E. (2004). Mining student data to characterize similar behavior groups in unstructured collaboration spaces. 16th European Conference on Artificial Intelligence, Valencia, Spain, August 22-27, 17-23.

Vatrapu, R., Tplovs, C., Fujita, N., \& Bull, S. (2011). Towards a visual analytics for teachers' dynamic diagnostic pedagogical decision-making. Proceedings of the First International Conference on Learning Analytics and Knowledge, Banff, Alberta, Canada, February 27-March 1, 93-98.

Venner, J. (2009). Pro Hadoop: Build scalable, distributed applications in the cloud. New York: Apress.

Watters, A. (2012, May 4). Learning analytics: Lots of education data... Now what? Message posted to http://hackeducation.com/2012/05/04/learning-analytics-lak12/

Wayman, J. C. (2005). Involving teachers in data-driven decision making: Using computer data systems to support teacher inquiry and reflection. Journal of Education for Students Placed at Risk, 10(3), 295-398.

Wayman, J. C., Cho, V., \& Richards, M. P. (2010). Student data systems and their use for educational improvement. In P. Peterson, E. Baker, \& B. McGraw (Eds.), International encyclopedia of education (3rd ed.) (pp. 14-20). Oxford, UK: Elsevier.

Whitaker, J. R. (2012). Responding to the need for intervention: Six easy steps prime students for mastery of science concepts. Science and Children, 50(4), 75-79.

Zuiker, S., \& Whitaker, J. R. (2013). Refining inquiry with multi-form assessment: Formative and summative assessment functions for flexible inquiry. International Journal of Science Education, 36(6), 1037-1059. doi:10.1080/09500693.2013.834489 